\title{
Cardiovascular disease in Africa: epidemiological profile and challenges
}

Ashley K. Keates ${ }^{1}$, Ana O. Mocumbi ${ }^{2}$, Mpiko Ntsekhe ${ }^{3}$, Karen Sliwa ${ }^{1,4}$ and Simon Stewart ${ }^{1,4}$

Abstract | From a global perspective, the large and diverse African population is disproportionately affected by cardiovascular disease (CVD). The historical balance between communicable and noncommunicable pathways to CVD in different African regions is dependent on external factors over the life course and at a societal level. The future risk of noncommunicable forms of CVD (predominantly driven by increased rates of hypertension, smoking, and obesity) is a growing public health concern. The incidence of previously rare forms of CVD such as coronary artery disease will increase, in concert with historically prevalent forms of disease, such as rheumatic heart disease, that are yet to be optimally prevented or treated. The success of any strategies designed to reduce the evolving and increasing burden of CVD across the heterogeneous communities living on the African continent will be dependent upon accurate and up-to-date epidemiological data on the cardiovascular profile of every major populace and region. In this Review, we provide a contemporary picture of the epidemiology of CVD in Africa, highlight key regional discrepancies among populations, and emphasize what is currently known and, more importantly, what is still unknown about the CVD burden among the $>1$ billion people living on the continent.

${ }^{\prime}$ Mary MacKillop Institute for Health Research, Australian Catholic University, Level 5, 215 Spring Street, Melbourne, Victoria 3000, Australia.

2Instituto Nacional de Saúde, Ministério da Saúde, Av. Eduardo Mondlane/Salvador Allende Caixa Postal 264. Maputo, Moçambique ${ }^{3}$ Division of Cardiology, Department of Medicine, University of Cape Town, Old Main Building, Groote Schuur Hospital, Observatory, Cape Town 7925, South Africa.

4Hatter Institute for Cardiovascular Research in Africa, Cape Heart Centre, 4th floor Chris Barnard Building, Faculty of Health Sciences, University of Cape Town, Observatory, Cape Town 7925 ,

South Africa.

Correspondence to S.S.

simon.stewart@acu.edu.au

doi:10.1038/nrcardio.2017.19

Published online 23 Feb 2017
Cardiovascular diseases (CVDs) were responsible for almost half of all deaths worldwide in 2008 (REF. 1). The majority of these deaths occurred in low-to-middle income countries ${ }^{2}$, with $>50 \%$ occurring in those aged $<70$ years $^{3}$. Africa is home to $>1$ billion people, and is a major contributor to the global burden of $\mathrm{CVD}^{4}$. In 2013, an estimated 1 million deaths were attributable to CVD in sub-Saharan Africa alone, which constituted 5.5\% of all global CVD-related deaths and $11.3 \%$ of all deaths in Africa ${ }^{5}$. CVD-related deaths contributed to $38 \%$ of all noncommunicable disease-related deaths in Africa, reflecting the growing threat of both noncommunicable disease and CVD. An almost twofold increase in the overall number of CVD-related deaths since 1990 has been reported, with a $>10 \%$ difference in mortality among women compared with men ${ }^{5}$. This dramatic change in the profile of CVD in Africa can be directly linked to population dynamics and epidemiological transitions among some of the most vulnerable communities in the world. Indeed, the largest proportion of the poorest billion individuals on the planet reside in sub-Saharan Africa, concentrated geographically along a 'central belt' stretching from West to East Africa, and incorporating many countries in Central Africa ${ }^{6}$. On the basis of these profound population statistics alone, the external factors that influence the health profile of these individuals across their life course should not be overlooked (BOX 1; FIG. 1).
In this Review, we outline the large-scale factors that influence global patterns of health and illness, and their particular relevance to the cardiovascular health of all Africans from a lifespan perspective. We also provide a contemporary overview of the cardiovascular risk profile of the African population. By presenting the historical pattern of CVD in Africa, we recognize the inherent difficulty and limitations in relying upon historical reports and projected data in such a large, dynamic, and heterogeneous population. On this basis, we provide contemporary epidemiological findings, where available, for each of the five geographical African regions (as defined by the United Nations ${ }^{7}$ )for the most commonly described forms of CVD from maternal, childhood, and adulthood perspectives. In providing these data, we identify important gaps in our knowledge of the epidemiology of CVD in Africa that are rarely acknowledged in reports on burden of disease. We also identify some of the challenges in addressing critical deficits in this area.

\section{Pathways to cardiovascular disease}

At the start of the 21st century, the disease prevalence of most of sub-Saharan Africa was characterized as being in the first stage of 'epidemiological transition', from a predominance of communicable disease towards a greater proportion of noncommunicable diseases ${ }^{8}$. 


\author{
Key points \\ - Socioeconomic forces beyond the individual's control influence the life-course of \\ cardiovascular disease (CVD); consistent with the phenomenon of epidemiological \\ transition, risk factors for CVD are high in many parts of Africa \\ - Historically, the number of epidemiological reports from Africa has been low, \\ with a predominance of projected estimates used to characterize the pattern \\ of cardiovascular risk and disease \\ - Major knowledge gaps include patterns of maternal cardiovascular health, \\ the prevalence and balance between congenital and acquired CVD in children, \\ and the spectrum of CVD in adulthood \\ - In many regions of Africa, the burden of cerebrovascular disease, cardiomyopathies, \\ and rheumatic heart disease still predominate, with HIV-related CVD presenting \\ a new communicable threat \\ - In more affluent regions, hypertensive heart disease and related heart failure \\ predominates, with emerging reports of previously scarce conditions such as \\ coronary artery disease, peripheral artery disease, and atrial fibrillation \\ - Compared with the global burden of CVD, affected Africans are typically younger, \\ predominantly female, and mostly from disadvantaged communities
}

\section{Hypertension}

Hypertension is a major driver of CVD in Africa, especially stroke and hypertensive heart disease ${ }^{18,19}$. A systematic review of 33 studies from 15 sub-Saharan African countries reported a prevalence range of $15-70 \%$ for hypertension for the period from 1999 to 2013 (REF. 20). The systematic review also highlighted the lack of hypertension awareness, treatment, and control in this region ${ }^{21}$. Based on current WHO estimates, the prevalence of hypertension is seemingly shifting towards the upper end of historical figures (typically $35-45 \%$ of adults) in all African regions, and will be a major contributor to highly preventable CVD events in the foreseeable future. A retrospective population study conducted in Gabon in 2005 involving 736 patients aged $\geq 40$ years reported that CVD was largely attributable to high rates of hypertension, with high blood pressure being predictive of stroke and peripheral arterial disease $(\mathrm{PAD})^{22}$.

\section{Hypercholesterolaemia}

WHO estimates that the global prevalence of hypercholesterolaemia (total cholesterol $>5 \mathrm{mmol} / \mathrm{l}$ ) for men and women to be $37 \%$ and $40 \%$, respectively, with little change in the past 25 years $^{23}$. Historically, the lipid profiles of African individuals were considered largely favourable, reflecting traditional lifestyles that include high levels of physical activity and diets low in fat, together resulting in low rates of atherosclerotic disease. Although the proportion of individuals aged $\geq 25$ years with hypercholesterolaemia in numerous Western African countries (such as Nigeria and Sierra Leone) is relatively low (15-20\%) compared with global averages, the rate of hypercholesterolaemia among those living in Northern African countries (such as Tunisia and Egypt) is closer to $45 \%{ }^{23}$. The prevalence for the rest of Africa typically ranges from $20 \%$ to $35 \%$ of the population, with women consistently having higher values. Beyond total cholesterol, a paucity of data exists on the lipid profile of individuals living in Africa. However, isolated studies from across Africa consistently report the phenomenon of low levels of HDL cholesterol in both men and women together with relatively high levels of LDL cholesterol and triglycerides ${ }^{24}$.

\section{Tobacco use}

Tobacco smoking is a leading contributor to the global burden of disease, particularly CVD. WHO data on the prevalence of tobacco smoking, available for 29 African countries, revealed a differential pattern of tobacco use across the continent ${ }^{15}$. For example, $45-50 \%$ of the adult population of Morocco and Egypt, $43-44 \%$ of Cameroon and the Republic of the Congo, and $44-60 \%$ of Mauritius and Sierra Leone reported tobacco use. By contrast, Ethiopia and Ghana had a lower prevalence of smokers (9\% and 13\%, respectively). Consistent with the rest of the world, smoking prevalence is consistently higher in men than women, as reflected by the predominance of smoking-related diseases among Tanzanian men ${ }^{16}$. The absolute number of smokers in sub-Saharan Africa alone is projected to increase by nearly 1.5 -fold to $>200$ million people by 2030 , with the prevalence of smoking among adolescents also on the rise ${ }^{17}$.

\section{Physical inactivity}

Although sedentary behaviour is frequently assessed in individuals living in high-income countries ${ }^{25}$, at present, very few reports on sedentary behaviours among African individuals have been described; activity levels are more often evaluated in this setting ${ }^{26,27}$. Surprisingly, data from a large survey on the physical activity levels of 57,000 individuals aged 25-64 years from 22 African countries from 2003 to 2009 suggested that African men and women were no more active than equivalent Asian, European, and North American cohorts $^{28}$. Activity type was predominantly related to employment and commuting, with very little leisure activity. The highest levels of activity were found in individuals living in Mozambique and Malawi (>90\% of the surveyed population meeting WHO-recommended activity levels) and the lowest in Mali and Mauritania 
(40-50\% meeting WHO-recommended activity levels) ${ }^{28}$. Cross-sectional studies of younger adults from African countries have consistently reported that less-thanoptimal activity levels are linked to increased BMI and blood pressure levels ${ }^{29-32}$.

\begin{abstract}
Obesity
The prevalence of obesity is markedly higher in African women than men, in contrast to other regions of the world ${ }^{33}$. WHO estimates for 2014 suggest that in much of Africa, obesity affects $<15 \%$ of adults, ranging from $2-10 \%$ in 31 countries and $10-15 \%$ in 15 other countries $^{33}$. Overall, obesity is more prevalent among women $(10-15 \%)$ than in men $(4-5 \%)$. The countries with the lowest prevalence of obesity are typically located in the poorest regions of Central and Western Africa. The prevalence of obesity in the ten African countries with the highest rates of obesity is consistent with that seen in high-income countries, including Egypt (29\%) and South Africa (27\%), reflecting the frequent dichotomy in risk and disease that is largely attributable to economic growth and epidemiological transition ${ }^{34}$. In many of these countries, an increase in weight profile among its residents has been directly implicated in rising cardiovascular risk levels from adolescence onwards ${ }^{29,35}$. Moreover, in Tunisia, where abdominal obesity levels rose by $\sim 70 \%$ in both men and women from 1997 to 2009, this adverse trend has been directly linked to increased mortality ${ }^{36}$.
\end{abstract}

\section{Diabetes mellitus}

The International Diabetes Federation World Atlas predicts that the number of individuals aged $20-79$ years with diabetes in Africa (predominantly type 2 diabetes) will rise from 14 million at present to 34 million by 2040 (REF. 37). The overall age-adjusted regional prevalence of diabetes is estimated to be $3.8 \%$. However, there are no reliable national figures for the majority of African

\section{Box 1 | Framework for determining cardiovascular health}

- The current and future cardiovascular health of most Africans is not only dependent on individual health choices, but on many external factors beyond their control ${ }^{213}$

- The poorest and most marginalized Africans (whether based on geography, age, or sex) have the least opportunity to optimize their health and longevity ${ }^{6}$

- Although the African environment is largely underdeveloped, around $10 \%$ of the overall disease burden is attributable to concerning levels of indoor and outdoor pollution, poor sanitation and hygiene, and overcrowding ${ }^{214}$

- Communicable forms of cardiovascular disease (particularly high levels of rheumatic heart disease) are likely to persist in the 21st century without profound socioeconomic change ${ }^{148}$

- Political instability (with high levels of corruption in many African countries) and economic uncertainties have an adverse effect on the potential application of innovative and cost-effective health programmes ${ }^{215,216}$

- Two-thirds of Africans do not have regular access to electricity, and it is often cheaper to eat unhealthy food ${ }^{217}$

- In countries such as Mozambique, limited government wealth and resources results in a reliance on overseas funding, with limited scope to address future health concerns ${ }^{218}$

- Simply providing more health services, without understanding how those services can be effectively utilized, is likely to benefit wealthier rather than poorer individuals ${ }^{219}$ countries, and up to two-thirds of African individuals with diabetes are thought to be undiagnosed - a figure close to double that of high-income countries. The age-adjusted prevalence of impaired glucose tolerance among African individuals is $9.1 \%{ }^{37}$. A dichotomy of diabetes prevalence exists, depending on age and sex, with a higher prevalence among African women aged 20-39 years and African men up to the age of 79 years.

\section{Dietary patterns}

Given the potential for hypertension linked to saltsensitivity in many African individuals ${ }^{38}$, excessive salt intake through the transition of diets from staple cereals, vegetables, and fruits to more processed foods poses a large health risk ${ }^{39}$. A study conducted in 2015 across 187 countries (including $>30$ African countries) examined trends in food intake from 1990 to 2010 (REF. 40). Low levels of healthy food consumption in combination with an increase in consumption of unhealthy foods (including fat-rich and sugar-rich diets linked to obesity, diabetes, and atherosclerosis) were observed in individuals living in low-income African countries. Individuals from middle-income African countries, such as South Africa, reported higher consumption of healthy foods, which was countered by a parallel increase in the consumption of unhealthy foods. Overall, those living in Central Africa consumed the least number of unhealthy items, whereas those with highest levels lived in the Southern and Northern Africa ${ }^{40}$. A WHO report on high-risk alcohol intake noted high abstinence rates in the predominantly Muslim populations of Northern Africa, in contrast to high rates of alcohol consumption (when compared with the rest of the world) in Southern Africa (including Namibia and South Africa ${ }^{41}$.

\section{Historical research reports in Africa}

For most of the 20th century, research reports on the cardiovascular health of Africans were limited, typically ranging from 50 to 100 publications (predominantly small case series) each year from the 1960s onwards ${ }^{42}$. Therefore, very limited historical data are available to describe the cardiovascular health and related maternal outcomes among African women ${ }^{43}$, despite pregnancy being a 'provocative' state with the possibility of unmasking or exacerbating subclinical CVDs with potentially fatal consequences (including congenital heart disease [CHD] and rheumatic heart disease $[\mathrm{RHD}])^{44-46}$. However, routine screening for CVD in pregnant African women remains scarce ${ }^{47}$. A high prevalence of postpartum cardiomyopathy in Africa has also been reported ${ }^{48,49}$. Among infants and children, CHD is a perennially reported cause of mortality. Case-fatality rates are exacerbated by a lack of resources for the rapid detection and treatment of affected infants with otherwise highly reversible defects (typically simple defects of left-to-right shunt physiology $)^{50,51}$. Among survivors, progression to heart failure ( $\mathrm{HF}$ ) is common both acutely and in later life $\mathrm{e}^{52,53}$. Given that left obstructive lesions are rarely diagnosed, the true epidemiology of CHD among this population is difficult to determine ${ }^{54}$. However, the reported incidence of $\mathrm{CHD}$ seems to be similar to that 


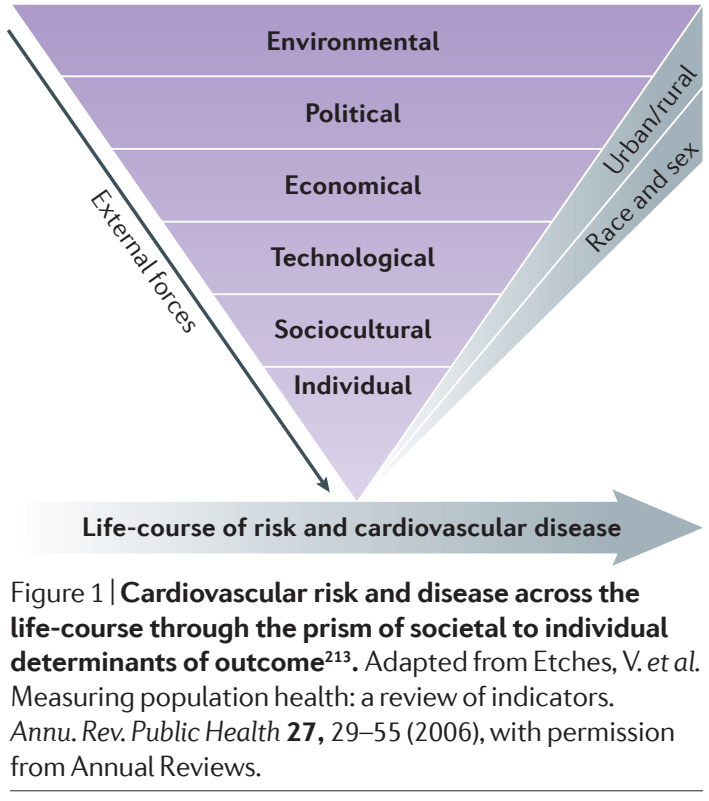

of high-income countries ( 8 cases per 1,000 births $)^{55}$. Hypocalcaemia, which results from vitamin D deficiency, has been suggested as a cause of the observed low prevalence of obstructive aortic lesions among those with $\mathrm{CHD}^{50}$. In some African countries, congenital abnormalities reportedly outnumbered acquired forms of heart disease (notably RHD) in children aged $<15$ years $^{56}$. However, this observation probably reflects late diagnosis and delayed referral to specialist cardiac care $^{57-59}$. Some acquired forms of heart disease remain unique or endemic to many parts of Africa. In poorer regions, endomyocardial fibrosis ${ }^{60}$, Takayasu arteritis ${ }^{61}$, and malnutrition-related cardiomyopathies (such as dilated cardiomyopathy) have been reported in endemic proportions among children and adolescents ${ }^{42}$. Other highly prevalent conditions include acute rheumatic fever, subsequent RHD (historical reports suggest $>10$ cases per 1,000 population in parts of Eastern and Central Africa ${ }^{62}$, with very high mortality ${ }^{63}$ ), tuberculous pericarditis, cardiomyopathies, and parasitic diseases.

Among adults, historical reports of the epidemiological profile of cardiac arrhythmias (including sudden cardiac death ${ }^{64}$ and atrial fibrillation $[\mathrm{AF}]^{65}$ ) have been surprisingly scarce ${ }^{6,67}$. Less surprising, given the historical risk profile of the African population, is the paucity of cases of coronary artery disease $(\mathrm{CAD})^{68,69}$. In addition, very few historical studies have reported on the incidence of $\mathrm{PAD}^{70}$. By contrast, HF and cardiomyopathies (notably dilated cardiomyopathy, rather than ischaemic cardiomyopathy) were commonly described in the African population in the latter half of the 20th centur $y^{66}$, with reports of HIV-related cardiomyopathy becoming increasingly common in the $1990 \mathrm{~s}^{71}$. HIV/AIDS, therefore, makes up one of a number of highly prevalent, communicable pathways to heart disease in Africa ${ }^{72}$. Notably, tuberculosis remains endemic throughout most parts of Africa, alongside malaria and bacterial infections $^{73}$. Tuberculosis-related heart disease that is associated with subacute effusive pericarditis (with or without cardiac tamponade or constrictive pericarditis) and concurrent $\mathrm{HF}$ is commonly observed ${ }^{74}$. In adults, late-stage RHD (resulting from acute rheumatic fever and acutephase pancarditis earlier in life $\mathrm{e}^{75}$ ) is an important legacy of childhood disease with little hope of prevention after the primary communicable event ${ }^{76,77}$. Adults affected by RHD typically progress from isolated mitral regurgitation in the first decade of life towards mixed valvular heart disease (VHD) by the third decade of life, which eventually leads to advanced $\mathrm{HF}^{78}$. Likewise, latent $\mathrm{CHD}$ in adults (for example, mitral valve prolapse, ventricular septal defect, and patent ductus arteriosus) comprise a substantial portion (typically 10-25\%) of all cases of CVD in adults ${ }^{79}$.

In contrast to other forms of CVD, research studies focusing on stroke in Africa have often been reported. Historically, cerebrovascular disease was identified as the single largest contributor to cardiovascular morbidity and mortality on the continent ${ }^{80-83}$, with mortality typically ranging from 100 to 150 deaths per 100,000 men, and 150 to 200 deaths per 100,000 women. After adjusting for age, disabling strokes are at least as common in Africa as they are in high-income countries (age-standardized rate of $114-315$ cases per 100,000 men, and $154-281$ cases per 100,000 women in sub-Saharan Africa) ${ }^{81}$.

\section{A regional perspective}

As indicated previously, many statistics outlined above derived from historical reports are not representative of the scale and diversity of the African continent and its people. We provide, therefore, a contemporary perspective of the epidemiology of CVD (including what is known and not known) on a regional basis. FIGURES 2-6 summarize and contrast some of the main sociodemographic statistics across $>50$ African countries according to the five main geographical regions identified by the United Nations ${ }^{7}$. From the smallest (Seychelles: population of 93,000) to the largest (Nigeria: population of 182 million) country, key statistics published by the World Bank include infant mortality ( $<50$ deaths per 1,000 live births among infants aged $0-5$ years in 20 countries to $>100$ deaths in eight countries), life expectancy (range 49-75 years), and proportion of the population living in poverty (range 9-77\%, with 49 and 84 million people living in poverty in the Democratic Republic of the Congo and Nigeria, respectively) ${ }^{84}$. Overall, these data demonstrate that nearly every African country struggled to achieve the Millennium Development Goals (eight goals which aim to improve the lives of the world's poorest individuals) by the 2015 target date ${ }^{85}$. Despite their critical importance, obtaining accurate health and social statistics from much of Africa is difficult and any data (including those presented in this Review) should be interpreted with care ${ }^{86}$, including the quoted poverty rates for each country (defined as the proportion of the population living on $<$ US\$1.25 per day measured at 2005 international prices and adjusted for purchasing power parity $)^{87}$. For each of the five geographical African regions, potential gaps relating to the contemporary burden and epidemiology of CVD in maternal health, infant and childhood health, and adult health are highlighted. 


\section{Northern regions of Africa}

The Northern region of Africa is often disregarded in reviews that typically focus on sub-Saharan Africa alone. This region comprises the seven diverse countries of Algeria, Egypt (largest population), Libya, Morocco, Sudan, Tunisia, and the disputed state of Western Sahara (smallest population and least-developed in the region; BOX 2; FIG. 2). Individuals living in Northern Africa have the highest life-expectancy and wealth compared with those living elsewhere in Africa ${ }^{84}$. However, a number of countries including Sudan and Western Sahara remain poverty-stricken.

\section{Maternal health}

Few contemporary studies on maternal cardiovascular health in Northern Africa have been reported. Notably, a $57 \%$ decline in the maternal mortality ratio has been observed during the period from 1990 to 2013, from 160 to 69 maternal deaths per 100,000 live births ${ }^{88}$.

\section{Infant and childhood health}

Congenital heart disease. $\mathrm{CHD}$ has been the primary focus of contemporary cardiovascular research among infants and children living in this region. In Egypt, the prevalence of CHD was reported to be 1.01 cases per 1,000 school-aged children in the year 2000, with significantly more female than male cases (1.09 versus 0.94 per 1,000 cases, respectively) ${ }^{89}$. However, these figures were reduced by half compared with those recorded for CHD in 1994 (2.6 cases per 1,000 school-aged children ${ }^{90}$. The most common types of CHD recorded in Egypt in 2000 were: ventricular septal defect (3.6 cases per 10,000 school-aged children), pulmonary stenosis $(1.9$ cases per 10,000$)$, and atrial septal defect $(1.4 \text { cases per } 10,000)^{89}$. The reported prevalence of CHD in school children in Sudan in the 1990s

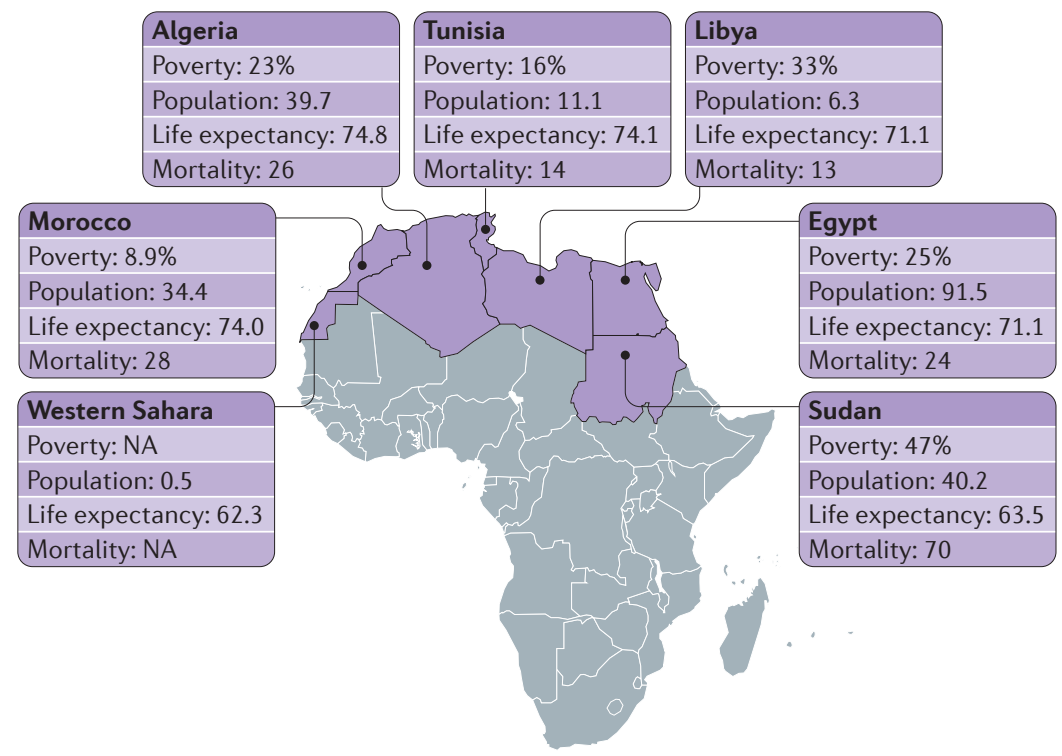

Figure 2 | Key sociodemographic statistics for Northern Africa. Population is displayed in millions, life expectancy in years, and mortality per 1,000 births $\leq 5$ years. NA, not available. was higher than that of Egypt (2 cases per 1,000), however, more up-to-date data are still awaited ${ }^{91}$. A similar study conducted in Tunisia examined the incidence of CHD among infants aged $\leq 2$ years (an analysis of $>37,000$ births from 2010 to 2011), and reported 6.8 cases of CHD per 1,000 live births, with the most common defects being ventricular septal defect, atrial septal defect, pulmonary stenosis, and atrioventricular septal defect ${ }^{92}$.

Rheumatic heart disease. From an acquired-disease perspective, the WHO global rheumatic fever/RHD prevention programme's contemporary phase (undertaken in 1994-2003 after a historical phase in 1986-1989) was conducted among school children in Sudan. The prevalence of RHD was 0.3 cases per 1,000 children in 2003 (REF. 93), which was much lower than the 3.4 cases per 1,000 children reported in the $1980 \mathrm{~s}^{90}$.

\section{Adult health}

Coronary artery disease. Between 1997 and 2009, CADrelated mortality in Tunisia increased from 70 to 87 deaths per 100,000 men and 28 to 41 deaths per 100,000 women $^{36}$. However, this increase was observed only in men aged $\geq 55$ years and in women aged $\geq 65$ years; a decline in CAD-related mortality was seen in the younger age groups ${ }^{36}$. In Sudan, the age-adjusted mortality from CAD in 2002 was estimated to be 205 deaths per 100,000 population ${ }^{93}$.

Cardiomyopathy and heart failure. The incidence of cardiomyopathies has also been explored in a hospital series based in Sudan. In 2009, 12\% of all admissions to the cardiology unit of a tertiary hospital were found to be attributable to an increasing number of cases of idiopathic dilated cardiomyopathy ${ }^{94}$.

Cerebrovascular disease and stroke. As noted in a review published in 2014, a relative paucity of data on stroke exists in Northern Africa, particularly from major urban centres ${ }^{95}$. Stroke contributes to $6 \%$ of all deaths in Egypt ${ }^{94}$. Apart from a large case series in Cairo, Egypt, involving 1,000 patients purposefully screened for substantial carotid disease (which reported a prevalence of $13.2 \%$ in patients aged $\geq 60$ years $)^{96}$, the most definitive data come from studies conducted in regional Egypt. In a prospective, community-based survey with purposeful sampling conducted in Qena, Egypt ( $n=8,027,52 \%$ male, and $70 \%$ aged $>20$ years), the age-adjusted prevalence of stroke was reported to be 777 cases per 100,000 local population (equivalent to 567 cases per 100,000 people for the Egyptian population). The crude rate of ischaemic stroke (797 cases per 100,000 population) was markedly higher than the rate of haemorrhagic stroke (125 cases per 100,000 population), and prevalence increased with age ( $>8 \%$ in those aged $\geq 70$ years). Remarkably, patients who were illiterate had a fivefold increased risk of stroke compared with literate counterparts ${ }^{97}$. In another regional study that involved door-to-door screening of individuals $(n=33,285)$, the annual incidence of stroke was 
found to be 1.8 cases per 1,000 population, with a prevalence of 655 cases per 100,000 population. A similar predominance of ischaemic strokes was observed, and the incidence increased with age ${ }^{98}$. In the 2008 RabatCasablanca Study ${ }^{99}$ in Morocco, a large populationbased study with purposeful sampling, a total of 127 cases of stroke were diagnosed within the study cohort of 44,742 individuals. The crude prevalence of stroke was highest among rural-dwelling compared with urban-dwelling people aged $>15$ years ( 338 versus 252 cases per 100,000 population). Ischaemic strokes were also predominant $(71 \%)$.

Congenital heart disease. The prevalence of CHD was assessed in a cohort of 522 Sudanese patients aged $0-65$ years. CHD was responsible for $87 \%$ of all cases of CVD, with acquired heart disease and rhythm disorders comprising the rest ${ }^{100}$.

\section{Eastern regions of Africa}

Eastern Africa is regarded as the most populous region on the continent and comprises 18 diverse countries that run along or parallel to the Indian Ocean, with a combined population of close to 400 million people (BOX 2; FIG. 3). Poverty levels are uniformly high across the region, with life expectancy typically ranging from 55 to 65 years.

\section{Maternal health}

In 2008, a 6-week, prospective, cross-sectional survey of 348 pregnant women (mean age 26.9 years) conducted in Keren, Eritrea using echocardiography found a $2.3 \%$ prevalence of subclinical RHD; most participants were otherwise asymptomatic. This prevalence is similar to that reported among school children in other developing countries ${ }^{101}$.

\section{Infant and childhood health}

Congenital heart disease. A number of hospital-based reports from the region have examined the pattern of children presenting with CVD. In a hospital series of 250 cases in Malawi (2009-2011), a predominance of children presented with CHD (56\%) as opposed to acquired heart disease $(44 \%)^{102}$. A further hospital series conducted in Uganda involving 194 patients aged 10 days to 15 years reported that the most common presentations of CHD were ventricular septal defects (25\%), patent ductus arteriosus (20\%), and tetralogy of Fallot (13\%). Notably, $27 \%$ of children aged $\leq 15$ years with CHD presented with an arrhythmia ${ }^{103}$. Another retrospective, hospital-based study from Uganda conducted during the period 2007-2011 explored the pattern of all forms of CVDs among children aged 4-15 years according to their echocardiographic profile. CHD was the most prevalent form of CVD (76\%), followed by RHD (46\%)

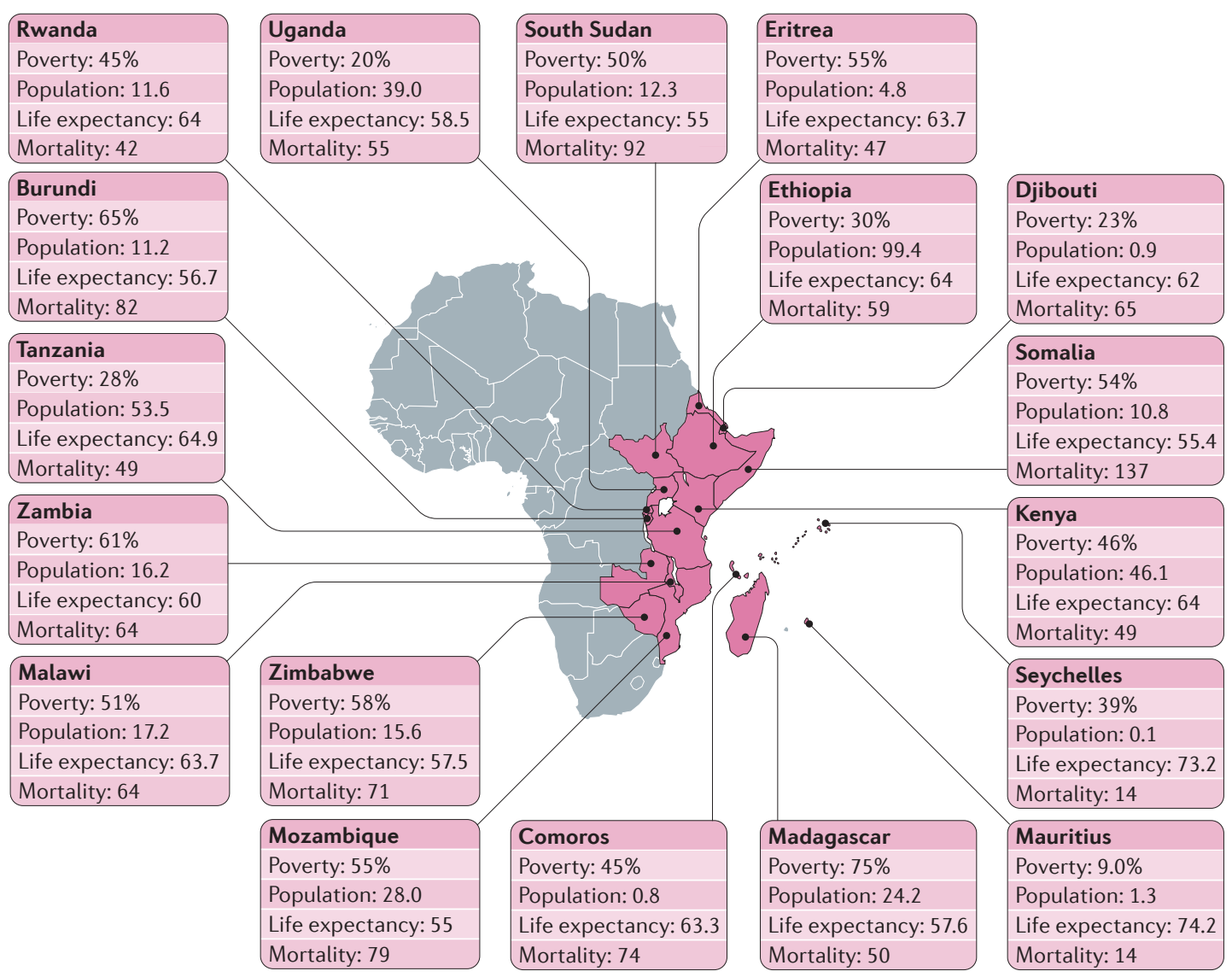

Figure 3 | Key sociodemographic statistics for Eastern Africa. Population is displayed in millions, life expectancy in years, and mortality per 1,000 births $\leq 5$ years. 


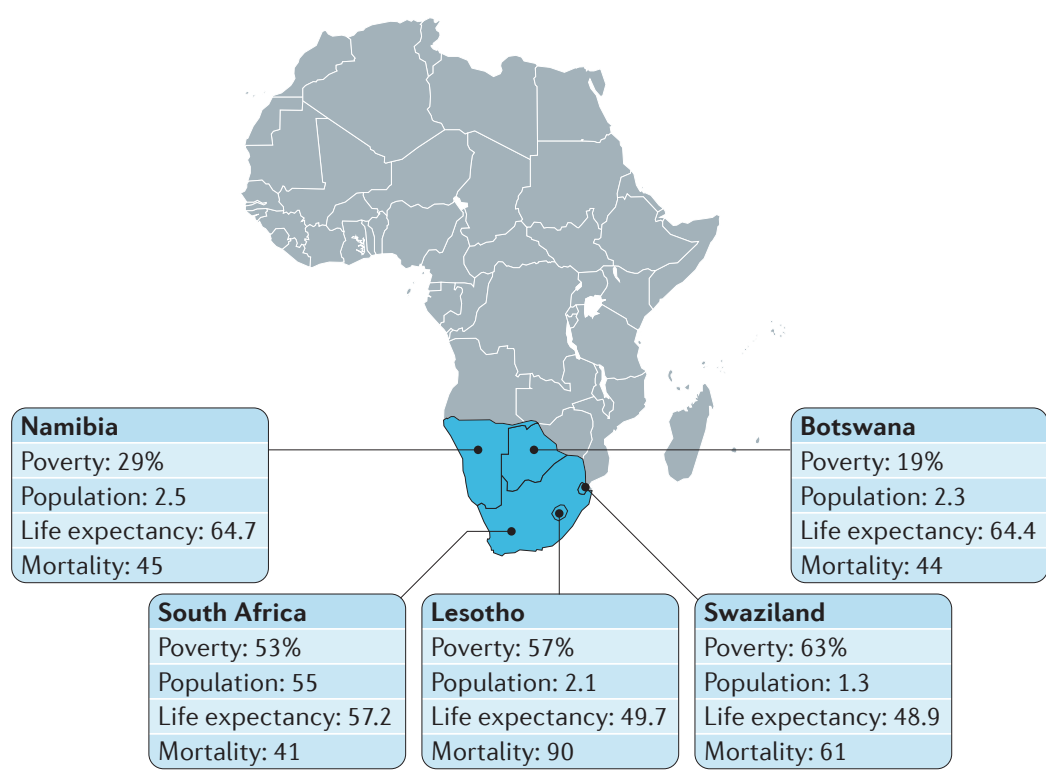

Figure 4 | Key sociodemographic statistics for Southern Africa. Population is displayed in millions, life expectancy in years, and mortality per 1,000 births $\leq 5$ years.

and dilated cardiomyopathy $(22 \%)^{104}$. A hospital-based study in Djibouti also examined the spectrum of CVD in 156 case-presentations in children aged 1 month to 15 years during the period 2009-2010. Overall, $20 \%$ of patients presented with CVD, and among these patients, most presented with CHD (84\%), followed by dilated cardiomyopathy (16\%) and RHD (1\%). The most common forms of CHD were ventricular septal defect (37\%) and isolated ventricular septal defect (19\%). Notably, 25\% of these patients were also HIV-positive ${ }^{105}$.

Rheumatic heart disease. A number of prospective, community-based surveys have also examined the prevalence of RHD in Eastern Africa. A 2010 cross-sectional, echocardiographic survey involving 4,869 primary school children aged 5-16 years in Kampala, Uganda, found a RHD prevalence of 14.8 cases per 1,000 children $(1.5 \%)^{106}$. Subsequent reports from Malawi $(n=1,450)$ and Ethiopia $(n=3,238)$ went on to assess RHD among children aged 5-18 years in 2014 and 2013-2015, respectively ${ }^{107,108}$. Malawi investigators reported a prevalence of $3.4 \%, 0.7 \%$, and $2.7 \%$ for latent, definite, and 'borderline' RHD, respectively ${ }^{107}$. The highest prevalence of RHD in this cohort was observed in those aged 11-13 years. Consistent with the earlier reports, the prevalence of definitive RHD was threefold higher than borderline RHD in the Ethiopian cohort (14 cases versus 5 cases per 1,000 children, respectively ${ }^{108}$. An echocardiographic study involving 488 HIV-positive children (aged 5-18 years; 53\% female) in Kampala, Uganda, from 2012 to 2013 found that four children had latent RHD on the basis of World Heart Federation criteria, resulting in a $0.82 \%$ prevalence of latent $\mathrm{RHD}^{109}$. Furthermore, two children had definite RHD, and a further two had borderline RHD. An additional cross-sectional survey was conducted in 2012-2013 in Harare, Zimbabwe, involving 2,601 patients (aged 1-12 years) admitted to the paediatric medical unit found 31 children with RHD or acute rheumatic fever, resulting in an overall prevalence of 11.9 cases per 1,000 hospitalized children. Of the 85 patients hospitalized with cardiovascular-related conditions, $26 \%$ presented with chronic RHD. An additional 1,026 outpatients were included in this study and of these, $2 \%$ had chronic RHD ${ }^{110}$. Finally, an Eritrean population study conducted between 2007 and 2008 involving 684 children (mean age 16.7 years, $46 \%$ female) from nine high schools reported that $4 \%$ of students had definitive RHD, whereas 3.3\% had suspected RHD. An additional $23 \%$ of students presented with valve abnormalities, including mild aortic, mitral, or tricuspid regurgitation ${ }^{111}$.

\section{Adult health}

Spectrum of cardiovascular disease. A number of predominantly hospital-based studies have examined the overall pattern of CVD in adults in the region. An autopsy study $(n=145)$ in Kenya conducted between 2005 and 2009 found that CVD was the attributable cause of death in $13 \%$ of cases (mean age of 50 years with a male-tofemale ratio of 2.7:1), the main contributors being myocardial infarction (19\%) and cardiomyopathy (17\%). Infective pericarditis and RHD were responsible for 7.5\% and $6.7 \%$ of the deaths, respectively ${ }^{112}$. A retrospective study of 3,908 patients (aged from 2 months to 82 years) admitted to the cardiac clinic of a tertiary hospital in Malawi between 2001 and 2005 showed that RHD was the most common cardiac presentation (30\%), followed by hypertensive heart disease (24\%), and dilated cardiomyopathy $(18 \%)^{113}$. CHD accounted for $4 \%$ of CVDs. A similar spectrum of case-presentations was reported from Ethiopia from 2003 to 2008 (comprising 781 hospital cases with a mean age of 43.5 years), with the most prevalent CVDs being RHD (33\%), hypertensive heart disease (24\%), and dilated cardiomyopathy $(20 \%)^{114}$. In a retrospective case series of 40 children ( $70 \%$ female) presenting with infective endocarditis in Ethiopia from 2008 to 2013, all patients had concurrent RHD (49\%) or CHD $(51 \%)^{115}$. In contrast to these earlier reports, however, the most common echocardiographic abnormalities found among 1,028 adult patients presenting to a tertiary hospital in Ethiopia from 2011 to 2013 were associated with VHD $(45 \%)^{116}$. A distinctive age-related presentation of valvular dysfunction was observed, with younger individuals displaying RHD and older individual showing degenerative changes. Around one-third of patients were also found to have diastolic HF with hypertensive heart disease as the main contributor ${ }^{116}$. From a broader perspective, an analysis of hospital admissions in the 30-year Medical-ICU registry ${ }^{117}$ in Ethiopia $(n=500$; December to May of 1981-1982, 1991-1992, 2001-2002, and 2011-2012) reported that CVD accounted for $43 \%$ of presentations. The overall case fatality rate was $32 \%$.

Arrhythmias. A prospective, community-based, crosssectional survey undertaken in a rural district of Tanzania screened 2,232 men and women aged $\geq 70$ years for AF by electrocardiography ${ }^{118}$. Overall, 15 patients were diagnosed with $\mathrm{AF}$ (12 women), equating to a crude prevalence of $0.67 \%$ (age-adjusted prevalence of $0.64 \%$ ). 


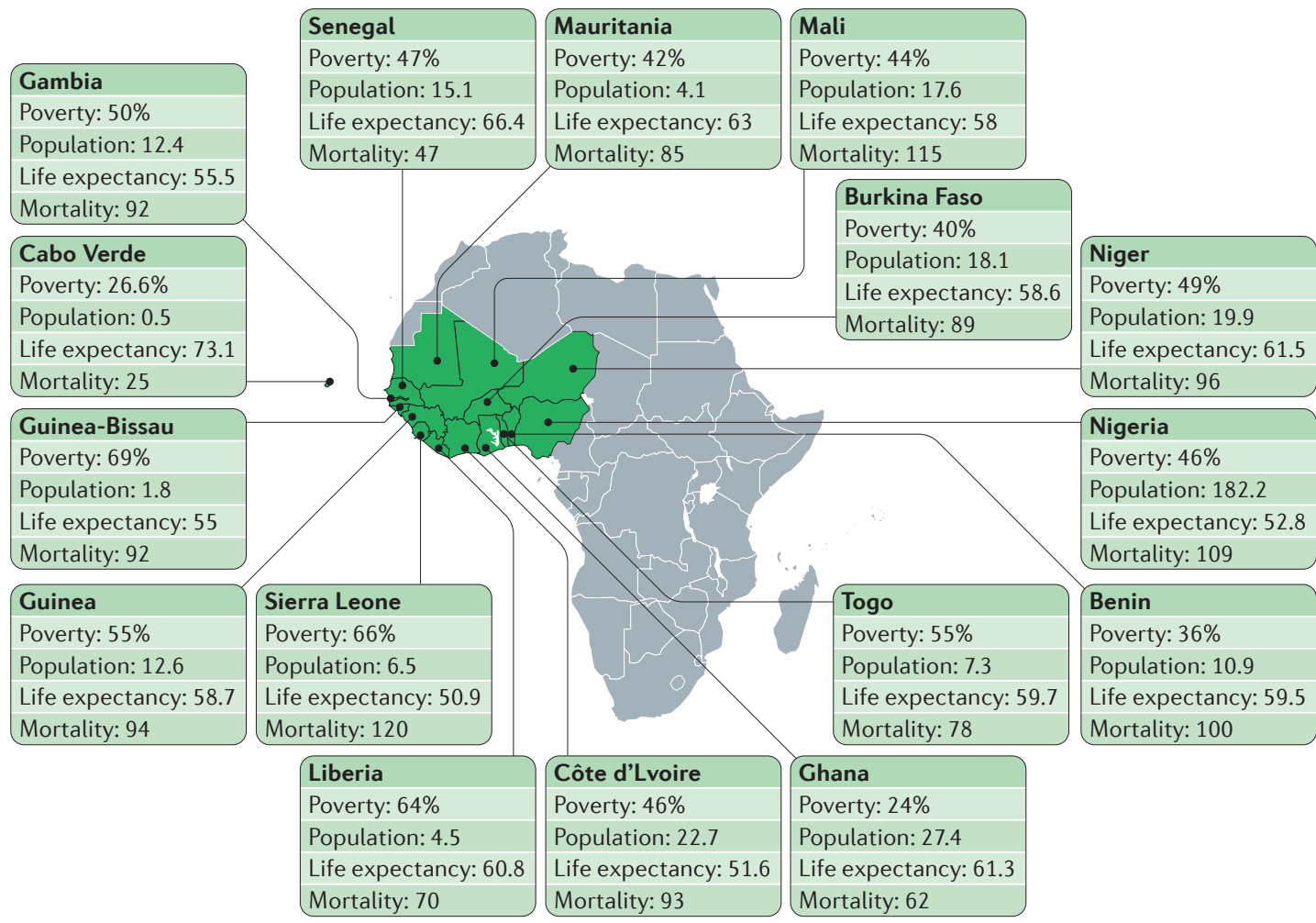

Figure 5 | Key sociodemographic statistics for Western Africa. Population is displayed in millions, life expectancy in years, and mortality per 1,000 births $\leq 5$ years.

The AF prevalence was higher in women than in men $(0.96 \%$ versus $0.31 \%)$; however, 1 -year mortality was higher in men than in women ( $67 \%$ versus $50 \%)$. Overall prevalence of AF increased with age from $0.46 \%$ in those aged $70-74$ years to $1.3 \%$ in those aged $\geq 85$ years ${ }^{118}$. A retrospective, observational hospital survey of AF was also conducted in Nairobi, Kenya, from 2008 to 2010. Among the 162 patients included in the study (mean age 67 years; $56 \%$ male); $40 \%$ presented with paroxysmal AF, $20 \%$ with persistent AF, and $40 \%$ with permanent AF. During the 6-month follow-up, mortality and the readmission rate were $6 \%$ and $12 \%$, respectively ${ }^{119}$.

Coronary artery disease. CAD has been recognized as an emerging health threat in Kenya ${ }^{120}$. A prospective study of 2,156 high-care patients admitted to a tertiary hospital in Nairobi, Kenya, between 2008 and 2010 found that $5.1 \%$ of admissions (mean age 64 years, $>75 \%$ male) were attributable to acute coronary syndrome (56\% with acute myocardial infarction with ST-segment elevation). The most common risk factors were hypertension ( $\sim 50 \%$ of patients) and smoking ( $25 \%)$; over one-third of patients also had type 2 diabetes ${ }^{121}$.

Cardiomyopathy and heart failure. The increasing importance of HF in the spectrum of CVD in the region has been highlighted by a number of contemporary studies. The 2013 Tanzania Heart Failure Study ${ }^{122}$ involving 521 patients reported that HF was associated with a mortality of 22.4 deaths per 100 person-years, with the most common aetiology being hypertension (45\%). A subsequent Ugandan study of the clinical characteristics and predictors of in-hospital mortality among 274 patients with HF found that the most common comorbidities were hypertension (36\%), HIV (11\%), chronic kidney disease (8\%), and type 2 diabetes $(7 \%)^{123}$. In-hospital mortality was $18.3 \%$, and the median length of hospitalization for patients who died was 2 days compared with 6 days for survivors, indicating a high burden of acuity and late-presenting HF in the overall cohort ${ }^{123}$.

Cerebrovascular disease and stroke. A large, prospective, hospital-based study investigated the epidemiological features of stroke events among 651 patients (mean age 59 years, $48 \%$ female, and $95 \%$ of African ancestry) in Maputo, Mozambique, from 2005 to 2006. Clinically confirmed stroke subtypes included subarachnoid haemorrhage (1.3\%), haemorrhagic stroke (40\%), and ischaemic stroke (58\%) $)^{124}$. Overall, $13 \%$ of stroke events occurred in individuals aged $<45$ years. Case-fatality rates were high, with a differential pattern among ischaemic versus haemorrhagic stroke and de novo versus recurrent events. Overall, 254 (50\%) patients died during the 28-day follow-up, with haemorrhagic stroke conferring a twofold to threefold higher risk of death. The overall incidence of stroke events in Maputo was 149 cases per 100,000 population per annum (equivalent to an age-standardized rate of 260 cases per 100,000 people aged $\geq 25$ years per annum). The incidence of haemorrhagic stroke plateaued in both men and women aged $>55$ years to $150-200$ events per 
100,000 people per annum, whereas ischaemic stroke events steadily increased with age (peaking at around 700 events per 100,000 people aged $>75$ years per annum $)^{124}$. Another prospective, hospital-based study was conducted at a tertiary referral hospital in Ethiopia (2013-2014) involving 163 patients with stroke (mean age 53 years and $66 \%$ male), and found an almost equivalent number of ischaemic versus haemorrhagic stroke presentations ${ }^{125}$. In-hospital stroke mortality was $14.7 \%$, with the main correlates of case-fatality being haemorrhagic stroke, stroke severity at admission, seizure, and decreased level of consciousness. Overall, the reported proportion of haemorrhagic stroke presentations in this cohort was markedly higher than in developed countries ${ }^{125}$. Similar findings were reported by the prospective Tanzanian Stroke Incidence Project that compared the pattern of cases of incident stroke in the rural community $(n=132)$ with that in the urban communities $(n=69)$ between 2003 and 2006. In both districts, $>80 \%$ of strokes were attributable to cerebral ischaemia, with the remainder being caused by cerebral haemorrhage, based on CT scans performed within 15 days of stroke (noting potential survivor bias) ${ }^{126}$.

\section{Southern regions of Africa}

Southern Africa comprises two geographically large, but sparsely populated countries (Namibia and Botswana), and two small kingdoms (Lesotho and Swaziland) surrounded by South Africa, the wealthiest and most populous country in the region (BOX 2; FIC. 4). There are marked differences in poverty levels $(20-60 \%$ of the population) and life-expectancy (49-65 years) across these five neighbouring countries. Not unexpectedly, much of epidemiological data from the region emanates from South Africa.

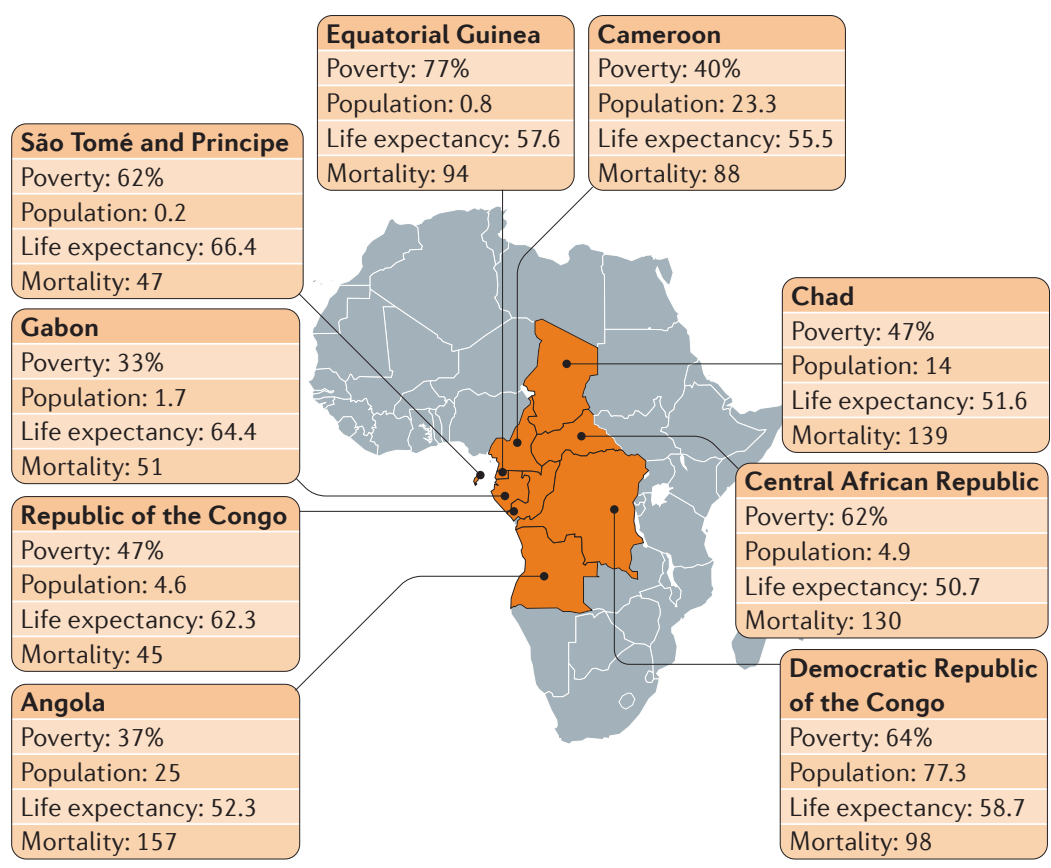

Figure 6 | Key sociodemographic statistics for Central Africa. Population is displayed in millions, life expectancy in years, and mortality per 1,000 births $\leq 5$ years.

\section{Maternal health}

Spectrum of cardiovascular disease. Maternal mortality in South Africa has quadrupled between 1998 and 2007 from 150 to 625 deaths per 100,000 live births ${ }^{127}$. An increase in the prevalence of CVD is thought to be an important contributor to this trend. A single-centre, 4-year, retrospective audit (2002-2005) of 189 pregnant women in South Africa found that around $1 \%$ of all pregnant women had underlying $\mathrm{CVD}^{128}$. Most cases were related to RHD, with HF being the most common presentation. Severe morbidity and case-fatality occurred in $12 \%$ and $3 \%$ of patients, respectively. A prospective study conducted from 2010 to 2012 in a single tertiary centre in South Africa examined the spectrum of CVD in 225 consecutive pregnant women (45\% African ancestry and $32 \%$ mixed ancestry, mean age 29 years $)^{43}$. Of those classified as WHO class I (patients without any limitation to physical activity; $n=73$ ), $35 \%$ were diagnosed with a minor or corrected form of CHD and $22 \%$ showed evidence of RHD. Of those presenting as WHO class II-IV (from patients presenting with a slight limitation to physical activity, to patients with pulmonary hypertension presenting with severe limitations to physical activity; $n=152$ ), $32 \%$ had CHD, $26 \%$ had RHD, and $27 \%$ had a cardiomyopathy (including postpartum cardiomyopathy, hypertensive HF, and idiopathic dilated cardiomyopathy). Other less common diagnoses were Takayasu arteritis, Marfan syndrome, ventricular arrhythmias, and constrictive pericarditis ${ }^{43}$. Overall, 5.9\% of patients died within 6 months. Perinatal mortality (death $<42$ days postpartum) in this cohort was 7 deaths per 1,000 live births. These data are largely consistent with a systematic review of seven studies of antenatal heart disease in South Africa ${ }^{129}$. Overall, the prevalence of heart disease ranged from 123 to 943 per 100,000 deliveries (median 616 cases per 100,000 deliveries). Rheumatic valvular lesions were the most common cardiac abnormalities. Peripartum case-fatality rates were highest in low-resource settings (9.5\%), whereas perinatal mortality ranged from $9-24 \%$.

\section{Infant and childhood health}

Congenital heart disease. A report on childhood health in South Africa identified CHD as a major contributor to death, accounting for 0.6-0.8 deaths per 1,000 live births, which was equivalent to 11,000 deaths each year ${ }^{130}$. Of those amenable to surgical intervention $(\sim 40 \%)$, survival to adulthood was estimated to be $\geq 85 \%$.

Rheumatic heart disease. A systematic review of the incidence, prevalence, and outcomes of RHD in South Africa in the past 2 decades reported a prevalence of 20.2 cases of asymptomatic RHD per 1,000 school children ${ }^{131,132}$.

\section{Adult health}

Spectrum of cardiovascular disease. The Heart of Soweto Study ${ }^{9,133}$ focused on a large urban community in South Africa undergoing epidemiological transition. An initial study of 4,162 cardiology presentations to the only tertiary referral hospital in Soweto in 2006 was undertaken, which included 1,593 de novo cases of heart disease (38\%) affecting proportionately more women (59\%), who were 


\section{Box 2 | Regional knowledge gaps}

\section{Northern Africa}

To our knowledge, no substantive cardiovascular-related research has been reported in the English literature from the countries of Algeria, Libya, and Western Sahara in the 21 st century. From a regional perspective, a paucity of data exists (particularly in relation to maternal cardiovascular health) relating to a broad range of cardiovascular diseases. Of note, the prevalence of heart disease in Sudan was estimated at $2.5 \%$ of the population in 2006 based on self-reported data from the Sudan Household Survey, an official government study ${ }^{93}$.

\section{Eastern Africa}

A number of Eastern African countries seem to be unrepresented in the literature from a cardiovascular research perspective, with the volume and spectrum of reports disproportionate to the size of the region.

\section{Southern Africa}

Relative to the other regions of Africa, the southern region is very well represented. However, most contemporary studies for this region are focused in South Africa, leaving the remaining countries with limited data on the epidemiology of CVD.

\section{Western Africa}

Like Southern Africa, Western Africa is very well represented in the literature and most forms of CVD across the lifespan are covered. However, despite some important reports from Senegal, Nigeria is equivalent to South Africa in its domination of regional research reports. Many countries in the region do not seem to have generated any substantial cardiovascular reports.

\section{Central Africa}

Limited cardiovascular reports are available for Angola, Chad, Democratic Republic of the Congo, Equatorial Guinea, and São Tomé and Príncipe, with relatively more data from Cameroon.
Arrhythmia. A retrospective review of a paramedic database covering the metropolitan region of Johannesburg in South Africa in the period from 2001 to 2007 identified 563 individuals (510 adults) who experienced out-of-hospital cardiac arrest, representing $3 \%$ of 17,507 recorded paramedic attendances (incidence of 6.4 events per 100,000 population per annum). In subsequent selected case reviews, $75 \%$ of cases were presumed to be of cardiac origin and $23 \%$ were associated with a shockable rhythm, the only independent predictor of survival ${ }^{136}$. In the Heart of Soweto Study ${ }^{137}$ (2006-2008), $4.6 \%$ of patients (mean age 59 years, $61 \%$ female, and $86 \%$ African ancestry) presented with AF that was confirmed with an electrocardiogram. Lone AF occurred in $8.9 \%$ of patients, whereas $44 \%$ had concurrent VHD. The estimated rate of incident AF presentations from Soweto was 5.6 cases per 100,000 population per annum, with $<1$ case per 100,000 population in those aged $15-24$ years, and $>50$ cases per 100,000 population in those aged $\geq 75$ years $^{137}$. These findings contrast with data from a multicentre registry across South Africa (29 centres) that analysed 302 cases of AF (mean age 67 years and $60 \%$ male) comprising a privately insured and affluent cohort ${ }^{138}$. The profile and outcomes of AF in these patients were similar to those seen in individuals with AF living in high-income countries. Among these patients, $66 \%$ had concurrent hypertension and a high burden of pre-existing CVD; 33\%, 8.3\%, and 5.3\% reported having $\mathrm{HF}$, stroke, or transient ischaemic attack in the previous year, respectively ${ }^{138}$.

on average 2 years younger than affected men (mean age of 53 years versus 55 years) $)^{9}$. HF was the most common primary diagnosis (44\%), and of those patients, $68 \%$ had a combination of hypertensive HF and dilated cardiomyopathy ${ }^{134}$. Hypertension was identified in $56 \%$ of the cohort, and was the primary diagnosis in $19 \%$ of patients. VHD was identified in $23 \%$ of the cohort (predominantly RHD), and was the primary diagnosis in $17 \%$ of patients. CAD was diagnosed in $10 \%$ of patients, with pericardial effusions, rhythm disorders, CHD, and stroke accounting for the remaining presentations $(9 \%)^{9}$. The balance between communicable and noncommunicable forms of heart disease was subsequently investigated in 5,328 patients with de novo CVD (88\% with African ancestry and $60 \%$ female). The prevalence of historically prevalent, communicable CVDs during the period 2006-2008 was $39 \%$ versus $35 \%$ of noncommunicable forms of heart disease (with a predominance of hypertensive heart disease). Clear trends in CVD presentation according to sex and residential status (born in the city of Soweto or in rural areas) were also evident. For example, patients aged $<50$ years predominantly suffered from 'traditional' forms of heart disease (19-60 cases per 100,000 population per annum); the prevalence for noncommunicable forms of heart disease was 5-45 cases per 100,000 population per annum. By contrast, patients aged $\geq 60$ years presented predominantly with noncommunicable heart disease (350 cases per 100,000 population per annum versus 211 cases per 100,000 population per annum for traditional forms of CVD). Overall, prevalence of traditional forms of heart disease was highest among women aged $\leq 39$ years who had migrated to Soweto ${ }^{135}$.
Coronary artery disease. A historical comparison study of CAD admissions to a tertiary hospital in Soweto identified 154 patients (42\% African ancestry) admitted to the hospital in 2004 with an acute coronary syndrome (troponin-positive) ${ }^{139}$. In the subsequent Heart of Soweto Study ${ }^{135}$ conducted in 2006-2008, CAD was diagnosed in 581 patients ( $11 \%$ of 5,328 patients presenting to the Cardiology Unit with substantial risk or disease); a lower prevalence was seen among those of African ancestry (5.9\%). The incidence of CAD was very low in those aged 20-39 years (150 cases per 100,000 population per annum). A specific analysis of 30 treatment-naive, HIVpositive patients with acute myocardial infarction (all of African ancestry and mostly young men with a mean age of 43 years) found that most patients had thrombus formation without underlying atherosclerosis, and few risk factors other than smoking ${ }^{140}$. Data from 615 South African patients admitted to hospital with an acute coronary syndrome from the ACCESS registry ${ }^{141}$ showed a 12 -month case-fatality rate of $5.7 \%$, with higher mortality observed in those aged $\geq 70$ years, with concurrent type 2 diabetes, or a history of cerebrovascular disease.

Cardiomyopathy and heart failure. In patients enrolled in the 2006 Heart of Soweto study (mean age 55 years, $57 \%$ female, and $87 \%$ African ancestry), HF was the predominant form of CVD among both prevalent (43\%) and de novo (44\%) cases. The most common diagnoses were hypertensive HF (33\%), idiopathic dilated cardiomyopathy (28\%), right HF (27\%), ischaemic 
cardiomyopathy (9\%), and HF owing to primary valve disease $(8 \%)^{134}$. A subanalysis of 761 patients of African ancestry presenting with hypertension $(n=761)$ showed a predominance of hypertensive HF (54\%), with left ventricular hypertrophy, renal dysfunction, and anaemia found in $39 \%, 24 \%$, and $11 \%$ of patients, respectively. Men were twice as likely to present with reduced ejection fraction than women. A high prevalence of right HF (28\%) was also found in this cohort; proportionately more men presented with right $\mathrm{HF}$ (15\% versus $12 \%)^{142}$. As highlighted by the subsequent PAPUCO study ${ }^{143,144}$, multiple pathways to the development of right $\mathrm{HF}$ existed, including chronic lung disease and tuberculosis, and pulmonary arterial hypertension (PAH; 20\%). A comparative, follow-up study in Cape Town involving patients with idiopathic dilated cardiomyopathy $(n=80)$ and familial dilated cardiomyopathy $(n=40)$ demonstrated some potentially important differences in clinical presentation, but both cohorts of patients had similar case-fatality in the long-term ( $40 \%$ mortality during median 5-year follow-up) $)^{145}$.

Communicable heart disease. Beyond RHD and cases of idiopathic dilated cardiomyopathy, HIV infection observed in the Heart of Soweto ${ }^{135}$ cohort made up $9.7 \%$ $(n=518)$ of the entire cohort. The mean age of this subset of patients was 39 years, $62 \%$ were women (on average 4 years younger than men), and $97 \%$ were of African ancestry. The major HIV-related CVD diagnoses were HIV-related cardiomyopathy (38\%), pericarditis or pericardial effusion (25\%), and HIV-related PAH $(8.1 \%)^{146}$. By contrast, a cross-sectional study in Botswana that included 179 patients (58\% female, aged $14-97$ years) from 2007 to 2008 found that the most common cardiac pathologies were cardiomyopathies (37\%), pericarditis (21\%), hypertensive heart disease (14\%), RHD (8\%), and right $\mathrm{HF}(7 \%)^{147}$. Of those with a cardiomyopathy $(n=66), 52 \%$ had a HIV-related cardiomyopathy, $20 \%$ had idiopathic dilated cardiomyopathy, and $29 \%$ had peripartum cardiomyopathy.

Valvular and rheumatic heart disease. A subanalysis as part of the Heart of Soweto Study ${ }^{148}$ (2006-2007) examined VHD in 4,005 patients and found that 960 had valvular abnormalities on echocardiography. Of these, 344 (36\%) patients (median age 43 years and 68\% female) had newly diagnosed RHD. Adults with latent RHD showed a transition from pure mitral involvement to mixed valvular dysfunction with increasing age. As expected, degenerative valvular disease was closely linked to advancing age. The overall estimated incidence of RHD in the region for those aged $>14$ years was 23.5 cases per 100,000 population per annum. However, a J-shaped distribution was evident with incidence rising from 15 cases to 53 cases per 100,000 population per annum from the age of 19 years upwards, but with the highest incidence among those aged $15-19$ years (30 cases per $100,000$ population per annum $)^{148}$. A systematic review of the limited available data in South Africa reported that 60-day and 180-day mortality post-admission with acute HF owing to RHD was $24.8 \%$ and $35.4 \%$, respectively ${ }^{132}$.
Overall, RHD-related mortality per 100,000 population was estimated to decrease from 1.27 to 0.7 between 1997 and 2012 in South Africa ${ }^{132}$.

Cerebrovascular disease and stroke. In 2008, 75,000 events of stroke were predicted to have occurred in South Africa, with 25,000 of these fatal within 1 month of the event ${ }^{149}$. The associated burden of disease owing to stroke was further estimated to be 564,000 disabilityadjusted life years ${ }^{149}$. As part of a continuing population-based surveillance study in a rural community northeast of South Africa (Agincourt north of Swaziland), the Southern Africa Stroke Prevention Initiative (SASPI) ${ }^{150}$ reported on the prevalence of survivors of stroke in 2001. Subsequently, 103 cases of stroke were found from 68,500 individuals subject to health surveillance. The crude prevalence of stroke was 243 cases per 100,000 population in those aged $\geq 15$ years, and 300 cases per 100,000 population when including all potentially positive cases. The male-to-female ratio was 1:1.8 (almost equal after agestandardization). A steep gradient in prevalence according to increasing age was observed. The overall prevalence of survivors of stroke in the community was 300 survivors per 100,000 population after adjusting for age $\mathrm{e}^{150}$. A subsequent report from the Agincourt surveillance site was used to quantify the burden of stroke in rural South Africa for the period from 2007 to 2011 (REF. 151). An estimated 842 incident cases of stroke occurred, equivalent to 244 cases per 100,000 person-years. Crude mortality was 114 deaths per 100,000 person-years. The projected burden of stroke among the 13 million rural-dwelling South Africans was 33,500 cases each year by 2011 (REF. 151). Overall, stroke accounted for $18 \%$ of deaths attributable to noncommunicable disease in South Africa (with 1.3-fold more deaths among those of African ancestry than among those of European ancestry $)^{152}$.

Peripheral artery disease. As part of SASPI ${ }^{153}$, a crosssectional study undertaken in South Africa (Limpopo province) analysed a random sample of 526 men and women aged $\geq 35$ years who were selected for cardiovascular screening in 2002. A subset of participants ( $n=322 ; 78 \%$ women, mean age 54 years; $22 \%$ male, mean age 59 years) were screened for PAD (defined as an ankle-brachial index $>0.9$ ). The prevalence of PAD increased with age, from $8.6 \%$ in those aged $<40$ years to $39.7 \%$ in those aged $>70$ years ${ }^{153}$. A purposefully selected, prospective cohort study of PAD reported in 2007 was undertaken in a regional hospital servicing the Eastern Cape of South Africa (a predominantly low socioeconomic population) ${ }^{154}$. Among 315 female and 227 male patients of African ancestry (mean age of 62 years) who attended the hospital's outpatient department, the overall prevalence of PAD was $29.3 \%$. Consistent with an outpatient population selected for screening, the prevalence of underlying risk factors was high, and included diabetes (30\%), smoking (31\%; predominantly male), obesity ( $38 \%$; predominantly female), and hypertension (75\%). Independent predictors of PAD were smoking (4.3-fold increased risk of PAD), diabetes (1.7-fold increased risk), and male sex (1.7-fold increased risk $)^{154}$. 


\section{Western regions of Africa}

The Western region of Africa is home to $>350$ million people, over half of whom reside in Nigeria, Africa's most populous country with the largest economy (BOX 2; FIG. 5). Apart from Nigeria, the region contains a number of small-to-medium countries (population 10-20 million people), many of which lie along the Atlantic Ocean. As with many regions in Africa, poverty levels vary, but are relatively high in comparison to the rest of the continent. Life-expectancy is typically 50-60 years. As expected, much of epidemiological data from the region emanates from Nigeria.

\section{Maternal health}

Spectrum of cardiovascular disease. A few notable reports have investigated the epidemiology of heart disease in pregnant women living in Western Africa. A study of 50 pregnant women with heart disease admitted to a tertiary hospital in Senegal over an 8-year period revealed RHD as the predominant pathology (92\%), of whom $15 \%$ had a previous surgical intervention. The remainder of the patients suffered from mitral stenosis. Nearly three-quarters of the cohort also presented with acute $\mathrm{HF}$ and $34 \%$ died during the 8 -year period, with those who received early surgical intervention more likely to survive. The effect on birth outcomes was profound, with only 30 live births from 50 pregnancies, and a median gestational age of 28 weeks ${ }^{155}$.

Cardiomyopathy and heart failure. In contrast to the poor outcomes reported from Senegal, a large retrospective hospital study conducted in southwest Nigeria that specifically focused on rates of HF among pregnant women reported more favourable outcomes. Overall, the study found a HF prevalence of 2.2 cases per 1,000 patients (typically second or third trimester) among 4,523 pregnant women during the period 2004-2010. Overall, two maternal deaths and three fetal or perinatal deaths were reported, with only one case of CHD and no cases of RHD ${ }^{156}$. A prospective study of 65 patients with postpartum cardiomyopathy in a tertiary hospital in northwest Nigeria (2003-2005) revealed a prevalence of 1 case per 102 births. Affected women (mean age 28.2 years) were predominantly multiparous, and of low socioeconomic status. These cases represented $60 \%$ of all cases of HF among women during the study period, with an associated case-fatality of $12.3 \%{ }^{157}$.

\section{Infant and childhood health}

Spectrum of cardiovascular disease. A retrospective study conducted in north-central Nigeria examined the pattern of childhood acquired heart disease relative to historical trends and data from other regions. Over a period of 10 years, 175 patients with CVD were identified (mean age 9.8 years and $54 \%$ female). RHD was the predominant cardiac pathology (58\%), along with dilated cardiomyopathy (19\%), which was most common in those aged $<5$ years. A range of other conditions were also diagnosed, including cor pulmonale or right $\mathrm{HF}(9.1 \%)$, pericardial disease $(8.6 \%)$, and infective endocarditis (4.6\%); $4 \%$ of patients also had concurrent $\mathrm{CHD}^{158}$.
A parallel study in northwestern Nigeria examined the pattern of acquired heart disease in 110 paediatric patients (comprising $2.9 \%$ of the 3,810 children assessed) diagnosed between 2009 and 2014 (REF. 159). The mean age of the patients was 10.4 years and $58 \%$ were male. Once again, RHD (43\%) and dilated cardiomyopathy with or without myocarditis (33\%) were the predominant causes of heart disease, with similar prevalence of pericardial effusion (11\%). Notably, endomyocardial fibrosis $(6.4 \%)$ and Kawasaki disease (1.8\%) were also diagnosed in this cohort. The overall mortality was $17.3 \%$. Another multicentre study conducted in Nigeria identified 116 children with acquired heart disease over a 42-month period (mean age was 6.7 years, $54 \%$ male). Compared with the preceding studies, this study reported a lower prevalence of RHD (17\%), with a more even distribution of dilated cardiomyopathy or myocarditis (29\%) and pericarditis (26\%). A further $14 \%$ of patients presented with hypertrophic cardiomyopathy, and 2.3\% with endomyocardial fibrosis ${ }^{160}$. In a cross-sectional study of 1,764 school children (mean age 8.9 years, $51 \%$ female) in southern Nigeria, only six $(0.34 \%)$ had a cardiac murmur detected on auscultation and, of these, only one (a boy from a poor socioeconomic background) had echocardiographically confirmed RHD (equating to a prevalence of 0.57 cases per 1,000 children $)^{161}$.

Congenital heart disease. A number of studies have examined the pattern of CHD among infants and children in Western Africa ${ }^{162,163}$. A retrospective study of 31,795 children attending the outpatient clinics of a tertiary hospital in Nigeria during the period 2007-2012 reported a prevalence of 2.2 cases per 1,000 children for $\mathrm{CHD}$, with the most common defect being isolated ventricular septal defect ${ }^{164}$. A similar study conducted in two hospitals in the Niger Delta region of Nigeria between 2009 and 2013 reported a higher prevalence of CHD (14.4 cases per 1,000 children), with ventricular septal defect also common ${ }^{165}$. A systematic review of reports from Nigeria suggested a $6 \%$ increase in ventricular septal defects every decade for the past 5 decades ${ }^{166}$. Similarly, a study of CHD and malnutrition in 40,123 children attending a tertiary outpatient clinic in Nigeria reported a prevalence of 12.5 cases per 1,000 children, with malnutrition evident in $92 \%$ of these cases $^{167}$. In a decade-long (2000-2010) multicentre study in Cote d'Ivorie of congenital abnormalities among 1,632 newborns, 1,725 congenital anomalies were recorded, indicating a frequency of 173 congenital abnormalities per year ${ }^{168}$. Furthermore, in a prospective, school-based screening study for RHD in Dakar, Senegal, in 2010 that included adolescents, the prevalence of RHD was 5.4 and 10.1 cases per 1,000 people in those aged 5-15 years and $16-18$ years, respectively ${ }^{169}$.

\section{Adult health}

Spectrum of cardiovascular disease. Two notable studies examined the spectrum of CVD presentations to a tertiary institution in the southern region of Nigeria. In 1,441 individual patients (mean age 54 years, $48 \%$ female) who underwent echocardiographic review 
during an 18-month period (2005-2007), hypertensive heart disease was detected in $57 \%$ of the cohort, RHD in $3.7 \%$, and dilated cardiomyopathy in $3.0 \%$. Other less common diagnoses were pericardial disease (1.8\%), cor-pulmonale or right $\mathrm{HF}(1.6 \%)$, CHD (0.6\%), and diabetic heart disease $(0.4 \%)^{170}$. Over a similar 3-year period (2007-2009) in southeast Nigeria, a total of 537 patients with CVD (mean age 61 years, $40 \%$ female) were identified from 3,546 medical admissions. Stroke (47\%) and $\mathrm{HF}(31 \%)$ were the predominant reasons for admission, with stroke contributing to 170 deaths. Hypertension was diagnosed in $21 \%$ of patients, whereas VHD with or without HF was present in $3.9 \%$ of patients ${ }^{171}$.

Arrhythmia. A retrospective study of sudden deaths was undertaken in southwest Nigeria over a 9-year period (2003-2011) ${ }^{172}$. Overall, sudden cardiac deaths accounted for $4 \%$ of 718 adult medical deaths (mean age 47 years, predominantly male), comprising $72 \%$ of out-of-hospital events. Of these deaths, $52 \%$ were attributable to CVD with hypertensive heart disease (87\%); left ventricular hypertrophy was present in $69 \%$ of these patients. Among those aged $\geq 50$ years, $39 \%$ had moderate-tosevere coronary atherosclerosis, with no cases of acute myocardial infarction found ${ }^{172}$. An ongoing surveillance study of a rural cohort in Ghana showed a low prevalence of $\mathrm{AF}(0.3 \%)$ among 924 patients aged $\geq 50$ years who underwent electrocardiographic screening ${ }^{173}$.

Coronary artery disease. A hospital-based, retrospective study of the prevalence and spectrum of CVD was conducted in northwest Nigeria during a 5-year period (2000-2005) $)^{174}$. Among 5,124 medical admissions, 1,347 (26-89\% of African ancestry, $72 \%$ male) were diagnosed with CVD. Of these, 46 (3.4\%) patients had CAD (overall prevalence of 9.0 cases per 1,000 population). The majority of the patients had underlying hypertension $(80 \%)$ and a substantial proportion had dyslipidaemia (44\%) and/or diabetes (35\%). The most common forms of clinical presentation were acute myocardial infarction (48\%), ischaemic cardiomyopathy (30\%), and angina pectoris $(22 \%)^{174}$. Consistent with these findings, an autopsy study of 747 coroner cases in southern Nigeria revealed a prevalence rate of 16 cases of CAD per 1,000 population, the majority of whom were male, urban-dwelling, of higher social class, and with multiple CVD risk factors ${ }^{175}$.

Cardiomyopathy and heart failure. A number of studies from Nigeria have examined the pattern of $\mathrm{HF}$ in hospital-based cohorts. The prospective Abeokuta Heart Failure Clinical Registry ${ }^{176}$ examined the profile of 452 patients with acute HF from the local population of 1 million people over a 2-year period (suggesting an incidence of 0.20 cases per 1,000 population per annum). The mean age of these patients was 57 years and $45 \%$ were female. Overall, $64 \%$ had a history of hypertension and $10 \%$ had diabetes; consequently, hypertensive HF was the most common aetiology (79\%). Less common causes of HF included dilated cardiomyopathy (7.5\%), cor pulmonale or right HF (4.4\%), pericardial disease
(3.3\%), RHD (2.4\%), and ischaemic heart disease (0.4\%). In-hospital mortality was $3.8 \%{ }^{176}$. In a similar study, 304 Nigerian patients presenting with $\mathrm{HF}$ (mean age 51 years, $49 \%$ female) in Abuja were also most likely to have hypertensive HF (62\%) ${ }^{177}$. A subsequent report involving 611 patients with the same predominance of hypertensive HF (diagnosed via echocardiography) over an 8-year period within the same institution found $45 \%(n=272)$ of patients had evidence of right ventricular dysfunction or right $\mathrm{HF}^{178}$.

Congenital heart disease. A study of 4,539 patients in southeast Nigeria over a 9-year period (2003-2012) reported a prevalence of $2.5 \%$ for $\mathrm{CHD}$ (determined by a retrospective review of echocardiography data). The most common lesions found were ventricular septal defects (31\%), atrial septal defects (29\%), and tetralogy of Fallot $(10 \%)^{179}$. A similar study conducted in western Nigeria $(n=76)$ confirmed that ventricular $(28 \%)$ and atrial (21\%) septal defects were the most common defects, along with patent ductus arteriosus (13\%) and tetralogy of Fallot $(12 \%)^{180}$.

Valvular and rheumatic heart disease. A retrospective study of all presentations of RHD to a tertiary hospital in southwest Nigeria was conducted over a 9-year period $(2003-2011)^{181}$. Of 9,423 case presentations related to heart disease, 11 patients with RHD (mean age 26 years, $55 \%$ male) were identified (prevalence of 0.16 cases per 1,000 population). Mitral valve defects were evident in ten patients (91\%), with mixed mitral and aortic lesions found in two patients (18\%). Concurrent HF was present in ten patients $(91 \%)^{181}$. A larger study in a tertiary hospital in southeast Nigeria found that $38 \%$ of 2,527 patients (mostly aged $\geq 30$ years and $45 \%$ female) referred for echocardiography over a 10-year period (1991-2001) had VHD. Mitral valve disease was the predominate aetiology (68\%), with the aortic valve affected in $25 \%$ of patients. RHD was the presumed aetiology in 59\% of cases ${ }^{182}$.

Peripheral arterial disease. In a cohort of 225 patients (mean age 61.4 years) in a tertiary hospital in Lagos, Nigeria, most of whom were being treated for type 2 diabetes, purposeful screening of PAD revealed an underlying prevalence of $40 \%{ }^{183}$. In a similar study involving 219 patients with diabetes (aged 50-89 years) in Nigeria, the prevalence of symptomatic PAD (claudication pain) was $28.7 \%$; the remaining asymptomatic patients were diagnosed with PAD based on an ankle-brachial index of $>0.90$ (REF. 184).

Cerebrovascular disease and stroke. A range of community and hospital-based studies have examined the epidemiological profile of stroke in the region ${ }^{185}$. In a 2007 prospective, community-based stroke registry examining de novo stroke events in southwest Nigeria, the crude incidence of stroke was found to be 25.2 cases per 100,000 population per annum (age-adjusted rate of 54.1 cases per 100,000 world population per annum $)^{186}$. Incidence rates were higher in men versus women (28.3 versus 21.3 cases per 100,000 population), with a mean 
age of 59 years in those affected. Among patients who were hospitalized, case-fatality was $16.2 \%{ }^{186}$. A prospective, cross-sectional survey in 2008-2009 of 15,155 individuals living in the economic capital of Benin (Cotonou) found a crude prevalence of 460 cases of stroke (mostly ischaemic) per 100,000 population (770 per 100,000 world population). The majority of patients (70\%) were aged between 45 and 74 years, and 54\% were male ${ }^{187}$. A similar study undertaken in the rural Niger Delta region in southern Nigeria reported a crude prevalence of stroke (undifferentiated by type) of 851 cases per 100,000 population ${ }^{188}$. The onset of stroke occurred earlier in this rural cohort on an age-adjusted basis compared with that derived from an equivalent urban cohort in Lagos, Nigeria ${ }^{189}$. In a large, retrospective study of 1,054 patients presenting with stroke (undifferentiated by type; mean age 64 years, 51\% male) to a major tertiary centre in the Ashanti region in Ghana (2006-2007), stroke constituted $9.1 \%$ of adult medical admissions. Case-fatality was $32.7 \%$ at 7 days and rose to $43.2 \%$ by 28 days $^{190}$.

\section{Central regions of Africa}

Central Africa consists of nine widely diverse populations, with the Democratic Republic of the Congo being the most populous (BOX 2; FIG. 6). Equatorial Guinea, one of the smallest countries in this region, has the highest reported poverty rate (77\%). Angola has the highest number of deaths per 1,000 births of those aged $<5$ years (157 deaths per 1,000 births).

\section{Infant and childhood health}

Communicable heart disease. A cross-sectional descriptive study focusing on the health consequences associated with HIV infection among 100 children aged $1-15$ years in Yaounde, Cameroon, found that $89 \%$ of the cohort presented with more than one cardiac abnormality: right ventricular dilatation was present in $76 \%$ of patients, left ventricular diastolic dysfunction in 32\%, left ventricular hypertrophy in $12 \%$, pericardial effusion in $11 \%$, and left ventricular systolic dysfunction in $2 \%$. Cardiac abnormalities were frequent in HIV-infected children, most of whom remained asymptomatic; routine echocardiography contributed to rapid diagnosis in this setting ${ }^{191}$.

Congenital heart disease. From 2002 to 2008, among 292 paediatric patients (mean age 10 years) with suspected cardiac pathologies and presenting to a major cardiosurgical centre in Cameroon that services the west and central regions of Africa, $96 \%$ had a confirmed diagnosis of $\mathrm{CHD}^{192}$. The most common lesions were isolated ventricular septal defect (38.8\%) and tetralogy of Fallot (26.1\%). A further retrospective study conducted in Cameroon from 2006 to 2009 among 505 patients (mean age 10 years, 55\% female) presenting to three urban referral centres in Douala, Shisong, and Yaoundé also confirmed CHD in $67.2 \%$ of patients, who had important differences in case presentation ${ }^{193}$. Interatrial septal defect, isolated pulmonary valve stenosis, and isolated ventricular septal defect were more commonly found in those presenting to the Douala centre. By contrast, ductus arteriosus, tetralogy of Fallot, congenital mitral valve regurgitation, coarctation of the aorta, double outlet right ventricle, atresia of the tricuspid valve, left isomerism, and anomalous pulmonary venous return were more commonly found in those presenting to the Shisong centre. Lastly, Ebstein disease arterial trunk and transposition of great arteries with ventricular septal defect was more commonly found in the Yaoundé cohort ${ }^{193}$.

Valvular and rheumatic heart disease. Echocardiographic data from children presenting to the largest referral hospital in Yaounde, Cameroon, over a 10-year period (2003-2013) were assessed ${ }^{194}$. A total of 65 children presenting with RHD were identified. The most common form of RHD was isolated mitral valve regurgitation (49\%), followed by the combination of mitral and aortic valve regurgitation $(35 \%)^{194}$. A retrospective study in Cameroon from 2005 to 2007 also examined the pattern of rheumatic valvulopathies among children and adolescents. Of the 262 patients aged 5-18 years presenting with abnormal echocardiographic data, $65 \%$ had RHD and $31 \%$ had $\mathrm{CHD}^{195}$. A similar study investigated cardiac aetiologies from 1,252 echocardiographic reports from a cardiovascular clinic in Cameroon (2008-2010). Overall, CHD was the most frequent CVD among patients aged $<10$ years (53\%), followed by RHD (29\%). The most common types of CHD were persistent ductus arteriosus (28\%), tetralogy of Fallot (21\%), and interatria or interventricular communication (21\%). Among those aged 10-19 years, RHD was the most common presentation $(62 \%)^{196}$.

\section{Adult health}

Spectrum of cardiovascular disease. Among patients aged 20-39 years presenting at a cardiovascular clinic in Cameroon, $53.3 \%$ presented with RHD and $27 \%$ presented with CHD $(27 \%)^{196}$. In those aged $40-49$ years, cardiomyopathies were the most prevalent cardiac aetiology (53\%), followed by pericarditis (27\%). Among those aged $\geq 50$ years (comprising $86 \%$ of the cohort), the most frequent cardiac aetiologies were hypertensive heart disease (48\%) and cardiomyopathy $(31 \%)^{196}$. Another retrospective population study was conducted in Gabon in 2005 that involved 736 patients aged $\geq 40$ years $^{22}$. CVD was identified in $13.3 \%$ of patients; prevalent cases accounted for $14.7-14.9 \%$ of all presentations, and incident cases for $11.5 \%$ and $8.9 \%$ of men and women, respectively.

Arrhythmia. The AFIB in Cameroon Study ${ }^{197}$, a counterpart of the AFIB Geneva Survey in Switzerland, was conducted from 2006 to 2007. In total, 172 patients aged $\geq 18$ years were included in the study. The most common subtypes of AF were permanent AF (56\%), followed by paroxysmal AF (23\%) and persistent AF (22\%). Underlying cardiac disorders were present in $91 \%$ of the patients, with hypertensive heart disease presenting in $48 \%$, VHD in $26 \%$, dilated cardiomyopathy in $16 \%$, and $\mathrm{CAD}$ in $6 \%{ }^{197}$. 
Table 1 | Large multinational studies of cardiovascular disease in Africa

\begin{tabular}{|c|c|c|c|c|}
\hline Study & Disease & Countries & Design & Main findings \\
\hline $\begin{array}{l}\text { Sub-Saharan } \\
\text { Africa Survey } \\
\text { of Heart Failure } \\
\text { Study } 205,206 \\
(2007-2010)\end{array}$ & $\begin{array}{l}\text { Acute } \\
\text { HF }\end{array}$ & $\begin{array}{l}\text { - Cameroon } \\
\text { - Ethiopia } \\
\text { - Kenya } \\
\text { - Mozambique } \\
\text { - Nigeria } \\
\text { - Senegal } \\
\text { - South Africa } \\
\text { - Sudan } \\
\text { - Uganda }\end{array}$ & $\begin{array}{l}\text { Prospective } \\
\text { observational survey } \\
\text { conducted in } 12 \\
\text { university hospitals } \\
\text { among patients with } \\
\text { confirmed acute HF } \\
\text { aged } \geq 12 \text { years }\end{array}$ & $\begin{array}{l}\text { - 1,006 patients were enrolled ( } 52 \pm 18 \text { years; } 51 \% \text { female; } \\
\text { 99\% African ancestry) } \\
\text { - Acute HF aetiology: hypertension } 45 \% \text {, anaemia } 15 \% \text {, RHD } 14 \% \text {, type } 2 \\
\text { diabetes } 11 \% \text {, ischaemic heart disease } 8 \% \text {, and atrial fibrillation } 8 \% \\
\text { - } 6 \text {-month mortality: } 17.8 \% \\
\text { - South African patients had higher number of events within } 60 \text { days }\end{array}$ \\
\hline $\begin{array}{l}\text { Pan-African } \\
\text { Pulmonary } \\
\text { Hypertension } \\
\text { Cohort } \\
\text { Study } \\
\text { (2011-2014) }\end{array}$ & $\mathrm{PAH}$ & $\begin{array}{l}\text { - Cameroon } \\
\text { - Mozambique } \\
\text { - Sigeria } \\
\text { - South Africa }\end{array}$ & $\begin{array}{l}\text { Prospective } \\
\text { multinational cohort } \\
\text { conducted in nine } \\
\text { specialist centres among } \\
\text { confirmed cases of PAH }\end{array}$ & $\begin{array}{l}\text { - } 209 \text { adults (median age } 48 \text { years, IQR 35-64 years) and } 11 \text { paediatric } \\
\text { patients (age range } 1-17 \text { years) } \\
\text { - } 66 \% \text { WHO class III-IV and right ventricular systolic pressure }(58 \mathrm{mmHg} \text {, } \\
\text { IQR } 49-74 \mathrm{mmHg} \text { ) } \\
\text { - } 16 \% \text { presented with PAH; of these, } 69 \% \text { were owing to left heart disease } \\
\text { and } 11 \% \text { to lung disease } \\
\text { 6-month case-fatality: } 21 \% \\
\text { - Paediatric patients were diagnosed with PAH associated CHD and left } \\
\text { heart disease }\end{array}$ \\
\hline $\begin{array}{l}\text { Pan-African } \\
\text { Sudden Cardiac } \\
\text { Death Survey } \\
\text { (Protocol paper) }\end{array}$ & $\begin{array}{l}\text { Sudden } \\
\text { cardiac } \\
\text { death }\end{array}$ & $\begin{array}{l}\text { - Cameroon } \\
\text { - Mozambique } \\
\text { - Nigeria } \\
\text { - South Africa }\end{array}$ & $\begin{array}{l}\text { Prospective, multicentre, } \\
\text { community-based } \\
\text { registry among all cases } \\
\text { of sudden cardiac death }\end{array}$ & $\begin{array}{l}\text { Potential findings will include the incidence, prevalence, and } \\
\text { characteristics of sudden cardiac death in a range of African countries } \\
\text { - Results are pending }\end{array}$ \\
\hline
\end{tabular}

$\mathrm{HF}$, heart failure; IQR, interquartile range; PAH, pulmonary arterial hypertension; RHD, rheumatic heart disease.

Cardiomyopathy and heart failure. Pulmonary hypertension was assessed in the urban population of Shisong, Cameroon, from 2013 to 2014 as part of the ongoing PAPUCO study ${ }^{198}$. Overall, $15.6 \%$ of the PAPUCO registry $(n=2,194)$ presented with pulmonary hypertension; 150 of these patients were included in the analysis (mean age was 62.7 years). Mean right ventricular systolic pressure was $68.6 \mathrm{mmHg}$; $7 \%$ presented with mild (36$50 \mathrm{mmHg}$ ), 29\% with moderate (51-60 mmHg), and 63\% with severe $(>60 \mathrm{mmHg}$ ) pulmonary hypertension. The two most common aetiologies of pulmonary hypertension were left heart disease (65\%) and RHD (36\%) ${ }^{198}$.

Communicable heart disease. A study conducted in Yaoundé, Cameroon, in 2014 examined the pattern of CVD among a cohort of 44 adults who were HIV-positive (mean age of 48 years, $70 \%$ receiving antiretroviral therapy $)^{199}$. HF was found to be the predominant clinical presentation (75\%), followed by pericardial effusion (46\%) and dilated cardiomyopathy (23\%). Furthermore, pulmonary hypertension was identified in $11.4 \%$ of patients ${ }^{199}$.

Cerebrovascular disease and stroke. A 14-year study on stroke admissions and case fatality was conducted from 1999 to 2012 in a major tertiary hospital in Yaoundé, Cameroon, which assessed a total of 1,688 stroke admissions confirmed by CT scan ${ }^{200}$. Overall, the number of cases of stroke increased from $34 \%$ in $1999-2000$ to $84 \%$ in 2011-2012.
Peripheral artery disease. Owing to the sparse data on PAD in Africa, which was mainly limited to urban areas, a cross-sectional survey focusing on PAD was conducted in two Central African countries from 2008 to 2009: the Central African Republic and the Republic of the Congo ${ }^{201}$. A total of 976 participants (mean age 73.6 years) were included in the analysis. The prevalence of PAD was $15 \%$ in the Central African Republic and 32\% in the Republic of the Congo, both increasing with age ${ }^{201}$. The cross-sectional, population-based EPIDEMCA study ${ }^{202}$ was conducted from 2011 to 2012 in the Central African Republic and the Republic of the Congo. Overall, 1,871 patients (aged $>65$ years) were studied and the prevalence of PAD was reported to be $14.8 \%$. The prevalence of PAD increased with age from $11 \%$ in patients aged $65-69$ years and $15 \%$ in those aged $70-74$ years to $22 \%$ in those aged $>80$ years, with higher rates in women. The differences in PAD prevalence between urban and rural areas were noteworthy in the Republic of the Congo (urban 21\% versus rural 14\%), but not in the Central African Republic (12\% versus 13\%) ${ }^{202}$.

\section{Pan-African perspective}

The historical capacity to conduct studies larger than single-centre studies focusing on specific disease states was limited from an African perspective. Much of the Global Burden of Disease ${ }^{4}$ data on an Africa-wide and country-by-country perspective provides only approximations of the relative burden of different forms of 
Table 2 | Large regional comparison studies of cardiovascular disease in Africa

\begin{tabular}{|c|c|c|c|c|}
\hline Study & Disease & Countries & Design & Main findings \\
\hline $\begin{array}{l}\text { HPTN024 } \\
\text { Trial Cohort }^{221} \\
\text { (2001-2003) }\end{array}$ & $\begin{array}{l}\text { Effect of } \\
\text { hypertension } \\
\text { on infant } \\
\text { outcomes }\end{array}$ & $\begin{array}{l}\text { - Malawi } \\
\text { - Tanzania } \\
\text { - Zambia }\end{array}$ & $\begin{array}{l}\text { Prospective, } \\
\text { randomized, } \\
\text { controlled trial } \\
\text { conducted in } \\
\text { four sites among } \\
\text { HIV-infected } \\
\text { pregnant women }\end{array}$ & $\begin{array}{l}\text { - } 2,126 \text { women enrolled } \\
\text { - Prevalent hypertension was extremely low at } 36 \text { weeks gestation (1.7\%) } \\
\text { - } 3.5 \% \text { still birth pregnancies, } 26 \% \text { preterm births, and low birth weight } \\
\text { in } 15 \% \text { of live births } \\
\text { - Neonatal death in } 4.3 \% \text { of live births } \\
\text { - Risk of still birth increased with a mean arterial pressure increment of } \\
5 \mathrm{mmHg} \text { by } 26-32 \% \text { during the period of } 20-36 \text { weeks of pregnancy }\end{array}$ \\
\hline $\begin{array}{l}\text { Stop RHD ASAP } \\
\text { Programme of } \\
\text { the Pan-African } \\
\text { Society of } \\
\text { Cardiology }{ }^{224} \\
\text { (Ethiopia } \\
\text { 2010-2013; } \\
\text { South Africa } \\
\text { 2008-2012) }\end{array}$ & RHD & $\begin{array}{l}\text { - Ethiopia } \\
\text { - South } \\
\text { Africa }\end{array}$ & $\begin{array}{l}\text { Two parallel, } \\
\text { prospective, } \\
\text { cross-sectional } \\
\text { screening of randomly } \\
\text { selected school pupils } \\
\text { (aged } 4-24 \text { years) } \\
\text { who underwent } \\
\text { echocardiography } \\
\text { assessment }\end{array}$ & $\begin{array}{l}\text { - Mean age of individuals from South Africa and Kenya are similar } \\
\text { (12.2 } \pm 4.2 \text { versus } 10.7 \pm 2.5 \text { years) } \\
\text { - Prevalence of RHD in South Africa and Ethiopia: } 20 \text { (95\% Cl 15-26) } \\
\text { versus } 31(95 \% \mathrm{Cl} 23-39) \text { cases per 1,000 population } \\
\text { - South African community with more individuals with African ancestry } \\
\text { and low socioeconomic status had equivalent RHD prevalence as } \\
\text { Ethiopian cohort: } 27 \text { ( } 95 \% \mathrm{Cl} 19-37) \text { versus } 13(95 \% \mathrm{Cl} 7.1-20) \text { cases } \\
\text { per } 1,000 \text { population }\end{array}$ \\
\hline
\end{tabular}

$\mathrm{HF}$, heart failure; RHD, rheumatic heart disease.

CVD, with highly variable confidence limits and projections ${ }^{203}$. Only in the past decade or so have more substantial multinational studies been undertaken to allow 'like-for-like' comparisons across the continent and against non-African countries. Importantly, some of these multicentre studies cover the absence of specific reports from regions such as Eastern Africa. However, studies such as the INTERHEART study ${ }^{204}$ are derived from ethnic and cultural minorities, as investigators struggle to collect data on those of African ancestry. Moreover, a majority of inter-African studies struggle to establish the capacity to generate data beyond specialist tertiary centres and countries such as Cameroon, Mozambique, Nigeria, and South Africa, largely relying upon the efforts of key individuals and teams who continue to generate a disproportionate amount of research data on CVD in Africa. TABLE 1 (large multinational studies), TABLE 2 (regional comparison studies), and TABLE 3 (international studies with a substantial African component) outline the major multinational studies that currently (or will in the immediate future) frame the epidemiology of CVD beyond an individual country or regional perspective.

\section{Cross-African comparisons}

The distribution of reports from Africa, from both geographical and spectrum-of-disease perspectives, are inconsistent and scarce when compared with the size of the continent and population. The addition of Africanspecific burden of disease estimates and an increasing number of multicentre surveillance studies (notably the THESUS study ${ }^{205,206}$ ) do not substantially alter this fact. Consequently, many unknowns with respect to providing a comprehensive and accurate picture of CVD in Africa exist. A robust and practical research framework for African researchers that allows meaningful, crossAfrican comparisons is critically needed. The WHO STEPwise approach to risk and disease surveillance is a particularly attractive option in this regard ${ }^{207}$.

In the meantime, meaningful epidemiological comparisons across the life-spectrum can be derived from individual studies. These examples highlight the value of being able to make such comparisons and, therefore, enhance the value of combining independent studies to draw larger conclusions. For example, in an urban community in Nigeria (where birth outcomes seem more favourable on a regional basis), the reported rate of pregnancy-related HF was 2.2 cases per 1,000 births, compared with 40 cases per 1,000 births in South Africa where surveillance and awareness of postpartum cardiomyopathy is much higher ${ }^{156,203}$. For birth outcomes, the reported rate of CHD per birth (noting differences in reporting live versus 'all' births) is fairly consistent across urban centres in Egypt, Nigeria, and South Africa (0.5-2.0 cases per 1,000 births $)^{87,130,164}$. By contrast, the rates are much higher in Tunisia ( $\sim$ cases per 1,000 
births $)^{92}$ and more rural regions of Nigeria ( 14 cases per 1,000 births $)^{165}$. Among schoolchildren, the reported prevalence of RHD is also fairly consistent (15-30 cases per 1,000 children screened) in the diverse countries of Ethiopia, Malawi, Nigeria, South Africa, and Uganda ${ }^{130}$. For adults, a limited number of studies provide directly comparable rates of CVD, with some notable exceptions. A prospective, surveillance study in Maputo, Mozambique (Eastern African), reported a rate of 150 strokes per 100,000 population per annum, with $40 \%$ attributable to cerebral haemorrhage, an almost 1:1 ratio of women to men, and a predominance of patients aged $<65$ years ${ }^{124}$. An ongoing, community-based surveillance study in rural South Africa (adjacent to Mozambique) reported a rate of 250 strokes per 100,000 population per annum. In both studies, case-fatality was high ${ }^{151}$.

\section{Responding to cardiovascular disease}

As noted in a 2016 report on the effect of socioeconomic status, ethnicity, and urbanization on the risk factor profiles of CVD in Africa ${ }^{203}$, considerable challenges exist in trying to achieve some of the aspirational goals to reduce CVD proposed by those both inside and outside Africa $^{54,208}$. For example, the Drakensberg Declaration on the control of RHD in Africa in 2006 outlined four main areas of activity to prevent and treat the disease effectively, one of which focused on improving the quality of data via more robust and systematic epidemiological surveillance ${ }^{209}$. A continental 'roadmap' of key actions that need to be taken by governments to eliminate acute rheumatic fever and eradicate RHD in Africa was designed and endorsed by the governments ${ }^{208}$. The main priorities of this document include surveillance,

Table 3 | Large international studies of cardiovascular disease including an African cohort

\begin{tabular}{|c|c|c|c|c|}
\hline Study & Disease & Countries & Design & Main findings \\
\hline $\begin{array}{l}\text { Global Rheumatic } \\
\text { Heart Disease } \\
\text { Registry } \\
(\text { REMEDY) } \\
(2010-2012)\end{array}$ & RHD & $\begin{array}{l}\text { - Ethiopia } \\
\text { - Kenya } \\
\text { - Malawi } \\
\text { - Namibia } \\
\text { - Mozambique } \\
\text { - Nigeria } \\
\text { - Rwanda } \\
\text { - South Africa } \\
\text { - Sudan } \\
\text { - Uganda } \\
\text { - Zambia }\end{array}$ & $\begin{array}{l}\text { Prospective hospital } \\
\text { registry conducted in } \\
25 \text { cardiac centres }\end{array}$ & $\begin{array}{l}\text {-3,343 patients (median age } 28 \text { years, } 66 \% \text { female) } \\
\text { - } 64 \% \text { multivalvular disease complicated by HF ( } 33 \% \text { ), } \\
\text { pulmonary hypertension ( } 29 \%) \text {, atrial fibrillation ( } 22 \%), \\
\text { and stroke ( } 7.1 \% \text { ) } \\
\text { - Women of child-bearing age in low-to-middle-income } \\
\text { countries were disproportionately represented } \\
\text { Paediatric patients were predominantly affected by pure } \\
\text { mitral regurgitation }\end{array}$ \\
\hline $\begin{array}{l}\text { INTERnational } \\
\text { Congestive Heart } \\
\text { Failure (INTER-CHF) } \\
\text { Study } 225 \\
\text { (2012-2014) }\end{array}$ & $\begin{array}{l}\text { Congestive } \\
\text { HF }\end{array}$ & $\begin{array}{l}\text { - Nigeria } \\
\text { - South Africa } \\
\text { - Sudan } \\
\text { - Uganda } \\
\text { - Mozambique } \\
\text { - Egypt (depicted } \\
\text { as Arabia) }\end{array}$ & $\begin{array}{l}\text { - Prospective registry } \\
\text { conducted in } 108 \\
\text { hospitals in } 16 \text { countries } \\
\text { - } 1,294 / 5,813 \text { ( } 22 \% \text { ) of } \\
\text { patients were from Africa }\end{array}$ & $\begin{array}{l}\text { - Patients with African ancestry ( } 52 \% \text { male and } 32 \% \text { rural) were } \\
\text { the youngest overall (mean age } 53 \text { years) } \\
\text { - Patients with African ancestry were more likely to be illiterate } \\
\text { (43\%) and be in NYHA class IV ( } 21 \% \text { ) } \\
\text { - HF aetiology: hypertensive HF } 35 \% \text {, ischaemic } \\
\text { cardiomyopathy 20\%, idiopathic dilated cardiomyopathy } \\
15 \% \text {, and RHD } 7 \%\end{array}$ \\
\hline $\begin{array}{l}\text { AFRICAN } \\
\text { INTER-HEART } \\
\text { STUDY204 } \\
(1999-2003)\end{array}$ & AMI & $\begin{array}{l}\text { - Benin } \\
\text { - Botswana } \\
\text { - Cameroon } \\
\text { - Kenya } \\
\text { - Mozambique } \\
\text { - Nigeria } \\
\text { - Seychelles } \\
\text { - South Africa } \\
\text { - Zimbabwe }\end{array}$ & $\begin{array}{l}\text { - Prospective case-control } \\
\text { study in } 52 \text { countries } \\
\text { - } 538 / 15,152 \text { ( } 3.6 \% \text { ) of the } \\
\text { study cohort were from } \\
\text { Africa: } 80 \% \text { South African } \\
\text { and } 36 \% \text { of African } \\
\text { ancestry }\end{array}$ & $\begin{array}{l}\text { - African patients were significantly younger than those from } \\
\text { the rest of the world }(52 \pm 12 \text { versus } 57 \pm 12 \text { years), with higher } \\
\text { BMI }\left(28 \pm 5 \mathrm{~kg} / \mathrm{m}^{2} \text { versus } 26 \pm 4 \mathrm{~kg} / \mathrm{m}^{2}\right) \text {, but lower lipid levels } \\
\text { - Risk factor profile: higher levels of hypertension }(+3 \%) \text {, } \\
\text { diabetes }(+5 \%) \text {, smoking }(+7 \%) \text {, and depression }(+8 \%) \\
\text { - Common risk factors for AMI found across all countries } \\
\text { - Risk of AMI increased with greater income and education, } \\
\text { and particularly hypertension in patients with African ancestry }\end{array}$ \\
\hline
\end{tabular}

$\mathrm{AMI}$, acute myocardial infarction; $\mathrm{HF}$, heart failure; RHD, rheumatic heart disease. 
provision of adequate supply of high-quality benzathine penicillin for the primary and secondary prevention of acute rheumatic fever and RHD, improved access to reproductive health services for women, and decentralization of technical expertise and technology for diagnosing and managing acute rheumatic fever and RHD ${ }^{209}$. The AFROStrep study ${ }^{210}$ is a collaborative multicentre study of clinical, microbiological, epidemiological, and molecular characteristics for group A streptococcal infection in Africa that comprises two components: active surveillance of group A Streptococcal pharyngitis cases from sentinel primary care centres (non-group A streptococcal infection); and passive surveillance of group A streptococcal disease from microbiology laboratories. A biorepository will be created to serve as a platform for vaccine development in Africa.

Beyond surveillance, the challenges of generating African-specific treatments for African-centric forms of CVD have been encapsulated by two trials. The IMPI trial $^{211}$, was a randomized, controlled trial of assessing the efficacy and safety of adjunctive immunotherapy for patients with tuberculous pericarditis. This condition is common, and is associated with effusive pericarditis with or without tamponade, constrictive pericarditis, and consequently poor outcomes ${ }^{74}$. Overall, the trial demonstrated that neither Mycobacterium indicus pranii nor prednisolone reduced the primary composite outcome of constrictive pericarditis, cardiac tamponade, or mortality. Prednisolone was, however, associated with reduced hospitalization and constrictive pericarditis in both HIV-positive and HIV-negative patients. However, when both treatments were given jointly, an increased incidence of HIV-related cancer in the study population was observed ${ }^{211}$. Such differential outcomes are indicative of the competing pathologies and treatments in complex cases in Africa that require careful hypothesis-testing. However, generating sufficiently experienced research sites and personnel, as well as carefully coordinating patients in a resource-poor health and social environment is not easy - as shown by the BA-HEF trial ${ }^{212}$, the first interventional, multicentre, multicountry, randomized HF study performed in Africa. Building on the landmark THESUS HF registry study ${ }^{205}$, investigators in the BA-HEF trial planned to test the efficacy (primary end point of death or HF readmission during 6-month follow-up) of combination hydralazine and nitrate versus placebo in 500 African patients admitted to hospital with acute HF. Unfortunately, after 4 years of recruitment, only 150 patients were recruited into the study and owing to the expiry of the study treatment, primary end point analyses had to be undertaken prematurely. Overall, the primary end point proved to be neutral (HR 1.05, 95\% CI $0.48-2.27, P=0.90$ for 133 randomized patients subject to intention-to-treat analyses). However, potentially insightful and important differences in secondary end points (including dyspnoea severity) were undermined by type II error. Many of the research sites were underfunded and lacked the expertise to conduct the trial successfully, in contrast to some of the highly successful observational registries highlighted in this Review ${ }^{212}$.

\section{Conclusions}

CVD poses unique challenges for the whole of Africa. Given the overwhelming burden of noncardiac-related infectious diseases (including malaria and the broader epidemic of HIV/AIDS), CVDs are often overlooked as a matter of health importance. Ultimately, a more comprehensive and accurate picture of the epidemiology of cardiovascular risk and CVD in Africa will require a substantial investment in a purposeful network of surveillance sites collecting standardized data across all parts of Africa. Much of the intellectual property for this strategy has been established through seminal studies such as the Heart of Soweto Study ${ }^{9}$, THESUS ${ }^{205}$, and REMEDY ${ }^{78}$, and planned studies such as the PanAfrican SCD study ${ }^{64}$. Investment in such a network is beyond the current resources of most African countries. Parallel to any health surveillance, such a network would provide two important benefits - first, collection of parallel socioeconomic data and, second, the capacity to undertake critically important, African-based trials (such as IMPI $^{211}$ and BA-HEF ${ }^{212}$ ) to generate Africanspecific evidence and clinical recommendations. Such activity would provide the platform to measure accurately the effect of all policies and interventions (from a societal to individual perspective and across the lifespan as outlined in FIG. 1) designed to improve the health of the African population from Morocco to South Africa.
1. World Health Organization. Global Action Plan for the prevention and control of noncommunicable diseases 2013-2020. WHO http://apps.who.int/iris/ bitstream/10665/94384/1/9789241506236 eng. pdf (2013)

2. Hosseinpoor, A. R. et al. Socioeconomic inequalities in risk factors for non communicable diseases in low-income and middle-income countries: results from the World Health Survey. BMC Public Health 12, 912 (2012).

3. Rani, M., Nusrat, S. \& Hawken, L. H. A qualitative study of governance of evolving response to noncommunicable diseases in low-and middle- income countries: current status, risks and options. BMC Public Health 12, 877 (2012).

4. Moran, A. et al. The epidemiology of cardiovascular diseases in sub-Saharan Africa: the Global Burden of Diseases, Injuries and Risk Factors 2010 Study. Prog. Cardiovasc. Dis. 56, 234-239 (2013).

5. Mensah, G. A. et al. Mortality from cardiovascular diseases in sub-Saharan Africa, 1990-2013: a systematic analysis of data from the Global Burden of Disease Study 2013. Cardiovasc. J. Afr. 26 S6-S10 (2015).

6. Kwan, G et al. Endemic cardiovascular diseases of the poorest billion. Circulation 133, 2561-2575 (2016).

United Nations Statistics Division. Composition of macro geographical (continental) regions, geographical sub-regions, and selected economic and other groupings. UNStats http://unstats.un.org/ unsd/methods/m49/m49regin.htm\#africa (2013).

8. Yusuf, S., Reddy, S., Ounpuu, S. \& Anand, S. Global burden of cardiovascular diseases: part I: general considerations, the epidemiologic transition, risk factors, and impact of urbanization. Circulation 104 2746-2753 (2001)

9. Sliwa, K. et al. Spectrum of heart disease and risk factors in a black urban population in South Africa (the Heart of Soweto Study): a cohort study. Lancet 371, 915-922 (2008).

10. Stewart, S. et al. The clinical consequences and challenges of hypertension in urban-dwelling black
Africans: insights from the Heart of Soweto Study Int. J. Cardiol. 146, 22-27 (2011).

11. Miller, V. et al. Availability, affordability, and consumption of fruits and vegetables in 18 countries across income levels: findings from the Prospective Urban Rural Epidemiology (PURE) study. Lancet Glob. Health 4, e695-e703 (2016).

12. Pisa, P., Behanan, R., Vorster, H. \& Kruger, A. Social drift of cardiovascular disease risk factors in Africans from the North West Province of South Africa: the PURE study. Cardiovasc. J. Afr. 23, 371-378 (2012).

13. Vorster, H. H., Kruger, A., Venter, C. S. Margetts, B. M. \& Macintyre, U. E. Cardiovascular disease risk factors and socio-economic position of Africans in transition: the THUSA study. Cardiovasc. J. Afr. 18, 282-289 (2007).

14. Egbujie, B. A., Igumbor, E. U. \& Puoane, T. A cross-sectional study of socioeconomic status and cardiovascular disease risk among participants in the Prospective Urban Rural Epidemiological (PURE) Study. S. Afr. Med. J. 106, 900-906 (2016). 
15. World Health Organization. Prevalence of tobacco smoking. WHO http://gamapserver.who.int/gho/ interactive charts/tobacco/use/atlas.html (2016).

16. Kidane, A., Hepelwa, A., Ngeh, E. T. \& Hu, T. W. Healthcare cost of smoking induced cardiovascula disease in Tanzania. J. Health Sci. (El Monte) 3 117-122 (2015)

17. Jha, P. \& Chaloupka, F. J. The economics of global tobacco control. BMJ 321, 358-361 (2000).

18. Muthuri, S. K., Oti, S. O., Lilford, R. J. \& Oyebode, O. Salt reduction interventions in sub-Saharan Africa: a systematic review. PLOS ONE 11, e0149680 (2016).

19. Schmidlin, O., Forman, A., Sebastian, A. \& Morris, R. C. Jr. Sodium-selective salt sensitivity: its occurrence in blacks. Hypertension 50, 1085-1092 (2007).

20. Addo, J., Smeeth, L. \& Leon, D. A. Hypertension in sub-saharan Africa: a systematic review. Hypertension 50, 1012-1018 (2007)

21. Ataklte, F. et al. Burden of undiagnosed hypertension in sub-saharan Africa: a systematic review and meta-analysis. Hypertension 65, 291-298 (2015)

22. Ngoungou, E. B. et al. Prevalence of cardiovascular disease in Gabon: a population study. Arch. Cardiovasc. Dis. 105, 77-83 (2012)

23. World Health Organization. Raised cholesterol: situation and trends. WHO http://www.who.int/gho/ncd/ risk_factors/cholesterol_text/en/ (2016).

24. Ulasi, I. I., ljoma, C. K. \& Onodugo, O. D. A communitybased study of hypertension and cardio-metabolic syndrome in semi-urban and rural communities in Nigeria. BMC Health Serv. Res. 10, 71 (2010).

25. Biddle, S. J. et al. Too much sitting and all-cause mortality: is there a causal link? BMC Public Health 16 635 (2016).

26. Kruger, H. S., Venter, C. S., Vorster, H. H. \& Study, T. Physical inactivity as a risk factor for cardiovascular disease in communities undergoing rural to urban transition: the THUSA study. Cardiovasc. J. S. Afr. 14, $16-23$ (2003).

27. Malan, L., Malan, N. T., Wissing, M. P. \& Seedat, Y. K. Coping with urbanization: a cardiometabolic risk? The THUSA study. Biol. Psychol. 79, 323-328 (2008)

28. Guthold, R. et al. Physical activity in 22 African countries: results from the World Health Organization STEPwise approach to chronic disease risk factor surveillance. Am. J. Prev. Med. 41, 52-60 (2011).

29. Ali, M., Yusuf, H. I., Stahmer, J. \& Rahlenbeck, S. I. Cardiovascular risk factors and physical activity among university students in Somaliland. J. Community Health 40, 326-330 (2015)

30. Baalwa, J., Byarugaba, B., Kabagambe, E. \& Otim, A. Prevalence of overweight and obesity in young adults in Uganda. Afr. Health Sci. 10, 367-373 (2010).

31. Magutah, K. Cardio-respiratory fitness markers among Kenyan university students using a $20 \mathrm{~m}$ shuttle run test (SRT). Afr. Health Sci. 13, 10-16 (2013).

32. Muhihi, A. et al. Physical activity and cardiovascular disease risk factors among young and middle-aged men in urban Mwanza, Tanzania. Pan Afr. Med. J. 11, 11 (2012).

33. World Health Organization. Global Health Observatory (GHO) data. WHO http://www.who.int/gho/ncd/risk factors/obesity text/en/ (2016).

34. Kruger, R., Kruger, H. S. \& Macintyre, U. E. The determinants of overweight and obesity among 10- to 15-year-old schoolchildren in the North West Province, South Africa - the THUSA BANA (Transition and Health during Urbanisation of South Africans; BANA, children) study. Public Health Nutr. 9, 351-358 (2006).

35. Stewart, S. et al. Elevated risk factors but low burden of heart disease in urban African primary care patients: a fundamental role for primary prevention. Int. J. Cardiol. 158, 205-210 (2012).

36. Saidi, O. et al. Analyzing recent coronary heart disease mortality trends in Tunisia between 1997 and 2009. PLOS ONE 8, e63202 (2013).

37. International Diabetes Federation. Diabetes Atlas: Africa. Diabetesatlas.org http://www. diabetesatlas.org resources/2015-atlas.html\# (2015).

38. Elijovich, F. et al. Salt sensitivity of blood pressure: a scientific statement from the American Heart Association. Hypertension 68, e7-e46 (2016).

39. Bibbins-Domingo, K. et al. Projected effect of dietary salt reductions on future cardiovascular disease. N. Engl. J. Med. 362, 590-599 (2010).

40. Imamura, F. et al. Dietary quality among men and women in 187 countries in 1990 and 2010: a systematic assessment. Lancet Glob. Health 3 , e132-e142 (2015).
41. World Health Organization. Global status report on alcohol and health. WHO http://www.who.int/ substance_abuse/publications/global_alcohol_report/ msbgsruprofiles.pdf (2011)

42. Stewart, S., Sliwa, S., Mocumbi, A., Damasceno, A $\&$ Ntsekhe, M. (eds) The Heart of Africa: Clinical Profile of an Evolving Burden of Heart Disease in Africa 35-68 (Wiley-Blackwell, 2016).

43. Sliwa, K. et al. Spectrum of cardiac disease in maternity in a low-resource cohort in South Africa. Heart 100, 1967-1974 (2014).

44. Nkomo, V. T. Epidemiology and prevention of valvular heart diseases and infective endocarditis in Africa. Heart 93, 1510-1519 (2007)

45. Kassebaum, N. J. et al. Global, regional, and national levels and causes of maternal mortality during 1990-2013: a systematic analysis for the Global Burden of Disease Study 2013. Lancet 384, 980-1004 (2014).

46. Sliwa, K., Johnson, M. R., Zilla, P. \& Roos-Hesselink, J. W. Management of valvular disease in pregnancy: a global perspective. Eur. Heart J. 36, 1078-1089 (2015).

47. Mocumbi, A., Sliwa, K. \& Soma-Pillay, P. Medical disease as a cause of Maternal mortality: the pre-imminence of cardiovascular pathology. Cardiovasc. J. Afr. 27, 84-88 (2016)

48. Hilfiker-Kleiner, D. \& Sliwa, K. Pathophysiology and epidemiology of peripartum cardiomyopathy. Nat. Rev. Cardiol. 11, 364-370 (2014).

49. Mocumbi, A. O. \& Sliwa, K. Women's cardiovascular health in Africa. Heart 98, 450-455 (2012).

50. Jaiyesimi, F. \& Antia, A. U. Congenital heart disease in Nigeria: a ten-year experience at $\mathrm{UCH}$, Ibadan. Ann. Trop. Paediatr. 1, 77-85 (1981)

51. Bannerman, C. H. \& Mahalu, W. Congenital heart disease in Zimbabwean children. Ann. Trop. Paediatr. 18, 5-12 (1998).

52. Ellis, J. et al. Echocardiographic, chest X-ray and electrocardiogram findings in children presenting with heart failure to a Ugandan paediatric ward. Trop. Doct. 37, 149-150 (2007)

53. Omokhodion, S. I. \& Lagunju, I. A. Prognostic indices in childhood heart failure. West Afr. J. Med. 24, 325-328 (2005).

54. Sani, M. U., Mukhtar-Yola, M. \& Karaye, K. M. Spectrum of congenital heart disease in a tropical environment: an echocardiography study. J. Natl Med. Assoc. 99, 665-669 (2007).

55. Marijon, E. et al. Prevalence of congenital heart disease in schoolchildren of sub-Saharan Africa, Mozambique. Int J Cardiol 113, 440-441 (2006).

56. Okoromah, C. A., Ekure, E. N., Ojo, O. O. Animasahun, B. A. \& Bastos, M. I. Structural heart disease in children in Lagos: profile, problems and prospects. Niger. Postgrad. Med. J. 15, 82-88 (2008).

57. Mocumbi, A. O. The challenges of cardiac surgery for African children. Cardiovasc. J. Afr. 23, 165-167 (2012)

58. Mocumbi, A. O. et al. Challenges on the management of congenital heart disease in developing countries. Int. J. Cardiol. 148, 285-288 (2011).

59. Zuhlke, L., Mirabel, M. \& Marijon, E. Congenital heart disease and rheumatic heart disease in Africa: recent advances and current priorities. Heart 99, 1554-1561 (2013).

60. Mocumbi, A. O., Ferreira, M. B., Sidi, D. \& Yacoub, M. H A population study of endomyocardial fibrosis in a rural area of Mozambique. N. Engl. J. Med. 359, 43-49 (2008).

61. Kechaou, M., Frigui, M., Ben Hmida, M. \& Bahloul, Z. Takayasu arteritis in southern Tunisia: a study of 29 patients. Presse Med. 38, 1410-1414 (in French) (2009)

62. Seckeler, M. D. \& Hoke, T. R. The worldwide epidemiology of acute rheumatic fever and rheumatic heart disease. Clin. Epidemiol. 3, 67-84 (2011).

63. Remenyi, B. et al. Position statement of the World Heart Federation on the prevention and control of rheumatic heart disease. Nat. Rev. Cardiol. 10, 284-292 (2013)

64. Bonny, A. et al. Rationale and design of the Pan-African Sudden Cardiac Death survey: the Pan-African SCD study. Cardiovasc. J. Afr. 25, 176-184 (2014).

65. Rahman, F., Kwan, G. F. \& Benjamin, E. J. Global epidemiology of atrial fibrillation. Nat. Rev. Cardiol. 11 , 639-654 (2014).

66. Sliwa, K., Damasceno, A. \& Mayosi, B. M. Epidemiology and etiology of cardiomyopathy in Africa. Circulation 112, 3577-3583 (2005)

67. Stambler, B. S. \& Ngunga, L. M. Atrial fibrillation in Sub-Saharan Africa: epidemiology, unmet needs, and treatment options. Int. J. Gen. Med. 8, 231-242 (2015).
68. Hertz, J. T. et al. Acute myocardial infarction in sub-Saharan Africa: the need for data. PLOS ONE 9, e96688 (2014)

69. Seedat, Y. K., Mayet, F. G., Latiff, G. H. \& Joubert, G. Study of risk factors leading to coronary heart disease in urban Zulus. J. Hum. Hypertens. 7, 529-532 (1993).

70. Johnston, L. E. et al. Peripheral arterial disease in sub-Saharan Africa: a review. JAMA Surg. 151, 564-572 (2016)

71. Longo-Mbenza, B., Seghers, K. V., Phuati, M. Bikangi, F. N. \& Mubagwa, K. Heart involvement and HIV infection in African patients: determinants of survival. Int. J. Cardiol. 64, 63-73 (1998).

72. Thienemann, F., Sliwa, K. \& Rockstroh, J. K. HIV and the heart: the impact of antiretroviral therapy: a global perspective. Eur. Heart J. 34, 3538-3546 (2013).

73. Petit, P. L. \& van Ginneken, J. K. Analysis of hospital records in four African countries, 1975-1990, with emphasis on infectious diseases. J. Trop. Med. Hyg. 98, 217-227 (1995)

74. Mayosi, B. M. Contemporary trends in the epidemiology and management of cardiomyopathy and pericarditis in sub-Saharan Africa. Heart 93 1176-1183 (2007)

75. Carapetis, J. R., McDonald, M. \& Wilson, N. J. Acute rheumatic fever. Lancet 366, 155-168 (2005).

76. Beaton, A. \& Sable, C. Health policy: reducing rheumatic heart disease in Africa - time for action. Nat. Rev. Cardiol. 13, 190-191 (2016).

77. Irlam, J., Mayosi, B. M., Engel, M. \& Gaziano, T. A Primary prevention of acute rheumatic fever and rheumatic heart disease with penicillin in South African children with pharyngitis: a cost-effectiveness analysis. Circ. Cardiovasc. Qual. Outcomes 6, 343-351 (2013).

78. Zuhlke, L. et al. Characteristics, complications, and gaps in evidence-based interventions in rheumatic heart disease: the Global Rheumatic Heart Disease Registry (the REMEDY study). Eur. Heart J. 36, 1115-1122a (2015).

79. Hodes, R. M. Pattern of heart disease in Ethiopia as seen in a cardiology referral clinic. Cardiology 75 458-464 (1988)

80. Muna, W. F. Cardiovascular disorders in Africa. World Health Stat. O. 46, 125-133 (1993).

81. Connor, M. D., Walker, R., Modi, G. \& Warlow, C. P. Burden of stroke in black populations in sub-Saharan Africa. Lancet Neurol. 6, 269-278 (2007)

82. Dgedge, M. et al. The burden of disease in Maputo City, Mozambique: registered and autopsied deaths in 1994. Bull. World Health Organ. 79, 546-552 (2001).

83. Truelsen, T. et al. Standard method for developing stroke registers in low-income and middle-income countries: experiences from a feasibility study of a stepwise approach to stroke surveillance (STEPS Stroke). Lancet Neurol. 6, 134-139 (2007).

84. The World Bank. World DataBank. Worldbank.org http://databank.worldbank.org/data/home.aspx (2016).

85. United Nations. Millennium development goals and beyond 2015. UN http://www.un.org/millenniumgoals/ (2016).

86. Okonjo-Iweala, N. \& Osafo-Kwaako, P. Improving health statistics in Africa. Lancet 370, 1527-1528 (2007)

87. World Health Organization. Atlas of African Health Statistics 2016: health situation analysis of the African Region. WHO http://www.aho.afro.who.int/sites/default files/publications/5266/Atlas-2016-en.pdf (2016).

88. United Nations Department of Public Information. The Millennium Development Goals Report. UN http:// www.un.org/millenniumgoals/2015_MDG Report/pdf/ MDG\%202015\%20rev\%20(July\%201).pdf (2015).

89. Bassili, A. et al. Congenital heart disease among school children in Alexandria, Egypt: an overview on prevalence and relative frequencies. J. Trop. Pediatr. 46, 357-362 (2000)

90. Refat, M. et al. A clinicoepidemiological study of heart disease in schoolchildren of Menoufia, Egypt. Ann. Saudi Med. 14, 225-229 (1994).

91. Gupta, I., Gupta, M., Parihar, A. \& Gupta, C Epidemiology of rheumatic and congenital heart diseases in school children. J. Indian Med. Assoc. 90 57-59 (1992)

92. Abid, D. et al. Congenital heart disease in 37,294 births in Tunisia: birth prevalence and mortality rate. Cardiol. Young 24, 866-871 (2014)

93. Suliman, A. The state of heart disease in Sudan Cardiovasc. J. Afr. 22, 191-196 (2011).

94. Abd-Allah, F. \& Moustafa, R. R. Burden of stroke in Egypt: current status and opportunities. Int. J. Stroke 9 1105-1108 (2014). 
95. Annual Bulletin of Mortality statistics. Central Agency for Public mobilization and Statistics (CAPMAS). CAPMAS http://www. capmas.gov.eg (2013)

96. Bishara, R. A., Taha, W., AlFarouk, M. O., Milik, I. A. \& Wilson, N. Screening for significant carotid artery disease among a cohort of 1,000 Egyptian patients. Vascular 16, 35-40 (2008).

97. Khedr, E. M. et al. Prevalence of ischemic and hemorrhagic strokes in Qena Governorate, Egypt: community-based study. J. Stroke Cerebrovasc. Dis. 23, 1843-1848 (2014)

98. El-Tallawy, H. N. et al. Epidemiology of non-fatal cerebrovascular stroke and transient ischemic attacks in Al Quseir, Egypt. Clin. Interv Aging 8, 1547-1551 (2013).

99. Engels, T. et al. Socioeconomic status and stroke prevalence in Morocco: results from the RabatCasablanca study. PLoS ONE 9, e89271 (2014).

100. Sulafa, K. M. \& Karani, Z. Diagnosis, management and outcome of heart disease in Sudanese patients. East Afr. Med. J. 84, 434-440 (2007).

101. Otto, H., Saether, S. G., Banteyrga, L., Haugen, B. O. $\S$ Skjaerpe, T. High prevalence of subclinical rheumatic heart disease in pregnant women in a developing country: an echocardiographic study. Echocardiography 28, 1049-1053 (2011)

102. Kennedy, N. \& Miller, P. The spectrum of paediatric cardiac disease presenting to an outpatient clinic in Malawi. BMC Res. Notes 6, 53 (2013).

103. Batte, A. et al. Prevalence of arrhythmias among children below 15 years of age with congenital heart diseases attending Mulago National Referral Hospital, Uganda. BMC Cardiovasc. Disord. 16, 67 (2016).

104. Lubega, S., Aliku, T \& Lwabi, P. Echocardiographic pattern and severity of valve dysfunction in children with rheumatic heart disease seen at Uganda Heart Institute, Mulago hospital. Afr. Health Sci. 14 617-625 (2014)

105. Massoure, P. L. et al. Cardiovascular disease in children in Dijibouti: a single-centre study. Pan Afr. Med. J. 14, 141 (2013).

106. Beaton, A. et al. Echocardiography screening for rheumatic heart disease in Ugandan schoolchildren. Circulation 125, 3127-3132 (2012).

107. Sims Sanyahumbi, A. et al. School and community screening shows Malawi, Africa, to have a high prevalence of latent rheumatic heart disease. Congenit. Heart Dis. 11, 615-621 (2016).

108. Yadeta, D. et al. Prevalence of rheumatic heart disease among school children in Ethiopia: a multisite echocardiography-based screening. Int. J. Cardiol. 221 260-263 (2016)

109. Gleason, B. et al. Brief report: prevalence of latent rheumatic heart disease among HIV-infected children in Kampala, Uganda. J. Acquir. Immune Defic. Syndr. 71, 196-199 (2016).

110. Gapu, P. et al. Rheumatic fever and rheumatic heart disease among children presenting to two referral hospitals in Harare, Zimbabwe. S. Afr. Med. J. 105 384-388 (2015)

111. Rossi, E., Felici, A. R. \& Banteyrga, L. Subclinical rheumatic heart disease in an Eritrean high-school population, detected by echocardiography. J. Heart Valve Dis. 23, 235-239 (2014).

112. Ogeng'o J. A., Gatonga, P. \& Olabu, B. O. Cardiovascular causes of death in an east African country: an autopsy study. Cardiol. J. 18, 67-72 (2011)

113. Soliman, E. Z. \& Juma, H. Cardiac disease patterns in northern Malawi: epidemiologic transition perspective. J. Epidemiol. 18, 204-208 (2008)

114. Habte, B., Alemseged, F. \& Tesfaye, D. The pattern of cardiac diseases at the cardiac clinic of Jimma University specialised hospital, South West Ethiopia. Ethiop. J. Health Sci. 20, 99-105 (2010).

115. Moges, T. et al. Infective endocarditis in Ethiopian children: a hospital based review of cases in Addis Ababa. Pan Afr. Med. J. 20, 75 (2015).

116. Adem, A. et al. Heart diseases in North Ethiopia pattern of echocardiographic abnormalities amon adult cardiac patients - an experience from Ayder Hospital of Mekelle University. Ethiop. Med. J. 52, 173-183 (2014)

117. Giday, A. \& Weldeyes, E. Trends in cardiovascular disease over time: a 30-year retrospective analysis of medical-ICU admissions in Addis Ababa, Ethiopia. Ethiop. Med. J. 53, 133-139 (2015).

118. Dewhurst, M. J. et al. Strikingly low prevalence of atria fibrillation in elderly Tanzanians J. Am. Geriatr. Soc. 60 1135-1140 (2012)
119. Shavadia, J. et al. Clinical characteristics and outcomes of atrial fibrillation and flutter at the Aga Khan University Hospital, Nairobi. Cardiovasc. J. Afr. 24 6-9 (2013).

120. Jablonski-Cohen, M. S., Kosgei, R. J., Rerimoi, A. J. \& Mamlin, J. J. The emerging problem of coronary heart disease in Kenya. East Afr. Med. J. 80, 293-297 (2003).

121. Shavadia, J., Yonga, G. \& Otieno, H. A prospective review of acute coronary syndromes in an urban hospital in sub-Saharan Africa. Cardiovasc. J. Afr. 23 318-321 (2012).

122. Makubi, A. et al. Contemporary aetiology, clinical characteristics and prognosis of adults with heart failure observed in a tertiary hospital in Tanzania: the prospective Tanzania Heart Failure (TaHeF) study. Heart 100, 1235-1241 (2014).

123. Okello, S., Rogers, O., Byamugisha, A., Rwebembera, J. \& Buda, A. J. Characteristics of acute heart failure hospitalizations in a general medical ward in Southwestern Uganda. Int. J. Cardiol. 176 1233-1234 (2014).

124. Damasceno, A. et al. An epidemiological study of stroke hospitalizations in Maputo, Mozambique: a high burden of disease in a resource-poor country. Stroke 41, 2463-2469 (2010).

125. Deresse, B. \& Shaweno, D. Epidemiology and in-hospital outcome of stroke in South Ethiopia. J. Neurol. Sci. 355, 138-142 (2015).

126. Walker, R. W. et al. A prospective study of stroke sub-type from within an incident population in Tanzania. S. Afr. Med. J. 5, 338-344 (2011).

127. Human Rights Watch. "Stop making excuses": accountability for maternal health care in South Africa. ReliefWeb http://reliefweb.int/sites/reliefweb.int/files/ resources/Full Report 2004.pdf (2011).

128. Soma-Pillay, P., MacDonald, A. P., Mathivha, T. M., Bakker, J. L. \& Mackintosh, M. O. Cardiac disease in pregnancy: a 4-year audit at Pretoria Academic Hospital. S. Afr. Med. J. 98, 553-556 (2008)

129. Watkins, D. A., Sebitloane, M., Engel, M. E. $\&$ Mayosi, B. M. The burden of antenatal heart disease in South Africa: a systematic review. BMC Cardiovasc Disord. 12, 23 (2012).

130. Bradshaw, D., Bourne, D. \& Nannan, N. MRC policy brief: what are the leading causes of death among South African children? UNICEF https://www.unicef.org/ southafrica/SAF_publications mrc.pdf (2003).

131. Zuhlke, L., Watkins, D. \& Engel, M. E. Incidence, prevalence and outcomes of rheumatic heart disease in South Africa: a systematic review protocol. BMJ Open 4, e004844 (2014).

132. Zuhlke, L., Engel, M. E., Watkins, D. \& Mayosi, B. M Incidence, prevalence and outcome of rheumatic heart disease in South Africa: a systematic review of contemporary studies. Int. J. Cardiol. 199, 375-383 (2015)

133. Stewart, S. et al. Mapping the emergence of heart disease in a black, urban population in Africa: the Heart of Soweto Study. Int. J. Cardiol. 108 101-108 (2006).

134. Stewart, S. et al. Predominance of heart failure in the Heart of Soweto Study cohort: emerging challenges for urban African communities. Circulation 118, 2360-2367 (2008)

135. Stewart, S., Carrington, M., Pretorius, S., Methusi, P. $\&$ Sliwa, K. Standing at the crossroads between new and historically prevalent heart disease: effects of migration and socio-economic factors in the Heart of Soweto cohort study. Eur. Heart J. 32, 492-499 (2011).

136. Stein, C. Out-of-hospital cardiac arrest cases in Johannesburg, South Africa: a first glimpse of short-term outcomes from a paramedic clinical learning database. Emerg. Med. J. 26, 670-674 (2009).

137. Sliwa, K et al. Predisposing factors and incidence of newly diagnosed atrial fibrillation in an urban African community: insights from the Heart of Soweto Study. Heart 96, 1878-1882 (2010)

138. Jardine, R. M., Fine, J. \& Obel, I. W. A survey on the treatment of atrial fibrillation in South Africa. S. Afr. Med. J. 104, 623-627 (2014).

39. Amira, C. et al. Emerging epidemic of cardiovascular disease among urban Africans: acute coronary syndrome at Baragwanath Hospital, Soweto. SA Heart J. 3, 7-11 (2006)

140. Becker, A. C. et al. Acute coronary syndromes in treatment-naive black South africans with human immunodeficiency virus infection. J. Interv. Cardiol. 23 , 70-77 (2010)

141. Schamroth, C. $\varnothing$ Access South Africa Investigators. Management of acute coronary syndrome in
South Africa: insights from the ACCESS (Acute Coronary Events - a Multinational Survey of Current Management Strategies) registry. Cardiovasc. J. Afr. 23, 365-370 (2012)

142. Stewart, S. et al. A not-so-rare form of heart failure in urban black Africans: pathways to right heart failure in the Heart of Soweto Study cohort. Eur. J. Heart Fail. 13, 1070-1077 (2011)

143. Thienemann, F. et al. Rationale and design of the Pan African Pulmonary hypertension Cohort (PAPUCO) study: implementing a contemporary registry on pulmonary hypertension in Africa. BMJ Open 4 e005950 (2014)

144. Thienemann, F. et al. The causes, treatment, and outcome of pulmonary hypertension in Africa: insights from the Pan African Pulmonary Hypertension Cohort (PAPUCO) Registry. Int. J. Cardiol. 221, 205-211 (2016).

145. Ntusi, N. B., Badri, M., Gumedze, F., Wonkam, A. \& Mayosi, B. M. Clinical characteristics and outcomes of familial and idiopathic dilated cardiomyopathy in Cape Town: a comparative study of 120 cases followed up over 14 years. S. Afr. Med. J. 101, 399-404 (2011).

146. Sliwa, K. et al. Contribution of the human immunodeficiency virus/acquired immunodeficiency syndrome epidemic to de novo presentations of heart disease in the Heart of Soweto Study cohort. Eur. Heart J. 33, 866-874 (2012).

147. Schwartz, T., Magdi, G., Steen, T. W. \& Sjaastad, I. HIV as a risk factor for cardiac disease in Botswana: a cross-sectional study Int Health 4, 30-37 (2012).

148. Sliwa, K. et al. Incidence and characteristics of newly diagnosed rheumatic heart disease in urban African adults: insights from the heart of Soweto study. Eur. Heart J. 31, 719-727 (2010).

149. Bertram, M. Y., Katzenellenbogen, J., Vos, T., Bradshaw, D. \& Hofman, K. J. The disability adjusted life years due to stroke in South Africa in 2008. Int. J. Stroke 8 (Suppl. A100), 76-80 (2013)

150. Connor, M. D. et al. Prevalence of stroke survivors in rural South Africa: results from the Southern Africa Stroke Prevention Initiative (SASPI) Agincourt field site. Stroke 35, 627-632 (2004)

151. Maredza, M., Bertram, M. Y. \& Tollman, S. M. Disease burden of stroke in rural South Africa: an estimate of incidence, mortality and disability adjusted life years. BMC Neurol. 15, 54 (2015).

152. Nojilana, B. et al. Emerging trends in noncommunicable disease mortality in South Africa, 1997-2010. S. Afr. Med. J. 106, 58 (2016).

153. Fowkes, F. G. et al. Distribution of a subclinical marker of cardiovascular risk, the ankle brachial index, in a rural African population: SASPI study. Eur. J. Cardiovasc. Prev. Rehabil. 13, 964-969 (2006)

154. Kumar, A., Mash, B. \& Rupesinghe, G. Peripheral arterial disease - high prevalence in rural black South Africans. S. Afr. Med. J. 297, 285-288 (2007).

155. Diao, M. et al. Pregnancy in women with heart disease in sub-Saharan Africa. Arch. Cardiovasc. Dis. 104 370-374 (2011)

156. Akinwusi, P. O., Adeniji, A. O., Atanda, O. O. $\Sigma$ Adekunle, A. D. Hospital-based incidence of materna heart failure during pregnancy in Nigeria. Int. J. Gen. Med. 6, 201-207 (2013).

157. Isezuo, S. A. \& Abubakar, S. A. Epidemiologic profile of peripartum cardiomyopathy in a tertiary care hospital. Ethn. Dis. 17, 228-233 (2007).

158. Bode-Thomas, F., Ige, O. O. \& Yilgwan, C. Childhood acquired heart diseases in Jos, north central Nigeria. Niger Med. J. 54, 51-58 (2013).

159. Sani, U. M., Ahmed, H. \& Jiya, N. M. Pattern of acquired heart diseases among children seen in Sokoto, North-Western Nigeria. Niger. J. Clin. Pract. 18 718-725 (2015)

160. Wilson, S. E., Chinyere, U. C. \& Queennette, D. Childhood acquired heart disease in Nigeria: an echocardiographic study from three centres. Afr. Health Sci. 14, 609-616 (2014).

161. Sadoh, W. E., Omuemu, V. O. \& Israel-aina, Y. T. Prevalence of rheumatic heart disease among primary school pupils in Mid-Western Nigeria. East Afr. Med. J. 90, 28-32 (2013).

162. Sadoh, W. E., Uzodimma, C. C. \& Daniels, Q. Congenital heart disease in Nigerian children: a multicenter echocardiographic study. World J. Pediatr. Congenit. Heart Surg. 4, 172-176 (2013)

163. Chinawa, J. M., Obu, H. A., Eke, C. B. \& Eze, J. C Pattern and clinical profile of children with complex cardiac anomaly at University of Nigeria Teaching Hospital, Ituku-Ozalla, Enugu State, Nigeria. Niger. J. Clin. Pract. 16, 462-467 (2013). 
164. Chinawa, J. M. et al. Synopsis of congenital cardiac disease among children attending University of Nigeria Teaching Hospital Ituku Ozalla, Enugu. BMC Res. Notes 6, 475 (2013)

165. Otaigbe, B. E. \& Tabansi, P. N. Congenital heart disease in the Niger Delta region of Nigeria: a four-year prospective echocardiographic analysis. Cardiovasc. J. Afr. 25, 265-268 (2014).

166. Abdulkadir, M. \& Abdulkadir, Z. A systematic review of trends and patterns of congenital heart disease in children in Nigeria from 1964-2015. Afr. Health Sci. 16, 367-377 (2016)

167. Arodiwe, I. et al. Nutritional status of congenital heart disease (CHD) patients: burden and determinant of malnutrition at university of Nigeria teaching hospital Ituku - Ozalla, Enugu. Pak. J. Med. Sci. 31, 1140-1145 (2015)

168. Kouame, B. D. et al. Epidemiology of congenital abnormalities in West Africa: results of a descriptive study in teaching hospitals in Abidjan: Cote d'Ivoire. Afr. J. Paediatr. Surg. 12, 51-55 (2015).

169. Kane, A. et al. Echocardiographic screening for rheumatic heart disease: age matters. Int. J. Cardiol. 168, 888-891 (2013).

170. Ogah, O. S. et al. Spectrum of heart diseases in a new cardiac service in Nigeria: an echocardiographic study of 1441 subjects in Abeokuta. BMC Res. Notes 1, 98 (2008).

171. Osuji, C. U., Onwubuya, E. I., Ahaneku, G. I. \& Omejua, E. G. Pattern of cardiovascular admissions at Nnamdi Azikiwe University Teaching Hospital Nnewi, South East Nigeria. Pan Afr. Med. J. 17, 116 (2014).

172. Akinwusi, P. O., Komolafe, A. O., Olayemi, O. O. ¿ Adeomi, A. A. Pattern of sudden death at Ladoke Akintola University of Technology Teaching Hospital, Osogbo, South West Nigeria. Vasc. Health Risk Manag 9, 333-339 (2013)

173. Koopman, J. J., Bodegom, D., Westendorp, R. G. J. \& Jukema, J. W. Scarcity of atrial fibrillation in a traditional African population: a community-based study. BMC Cardiovasc. Disord. 14, 87 (2014).

174. Sani, M. U. et al. Ischaemic heart disease in Aminu Kano Teaching Hospital, Kano, Nigeria: a 5 year review. Niger. J. Med. 15, 128-131 (2006)

175. Essien, O. E., Andy, J., Ansa, V., Otu, A. A. \& Udoh, A. Coronary artery disease and the profile of cardiovascular risk factors in South South Nigeria: a clinical and autopsy study. Cardiol. Res. Pract. 2014 804751 (2014).

176. Ogah, O. S. et al. Contemporary profile of acute heart failure in Southern Nigeria: data from the Abeokuta Heart Failure Clinical Registry. JACC Heart Fail. 2, 250-259 (2014)

177. Ojji, D. B., Alfa, J., Ajayi, S. O., Mamven, M. H. $\&$ Falase, A. O. Pattern of heart failure in Abuja, Nigeria: an echocardiographic study. Cardiovasc. J. Afr. 20, 349-352 (2009)

178. Ojji, D. B. et al. Right ventricular systolic dysfunction is common in hypertensive heart failure: a prospective study in sub-Saharan Africa. PLOS ONE 11, e0153479 (2016).

179. Ejim, E. et al. Congenital heart diseases in adults: a review of echocardiogram records in enugu, South-East Nigeria. Ann. Med. Health Sci. Res. 4 522-525 (2014)

180. Kolo, P. M., Adeoye, P. O., Omotosho, A. B $\varangle$ Afolabi, J. K. Pattern of congenital heart disease in Ilorin, Nigeria. Niger. Postgrad. Med. J. 19, 230-234 (2012).

181. Akinwusi, P. O., Peter, J. O., Oyedeji, A. T. $\&$ Odeyemi, A. O. The new face of rheumatic heart disease in South West Nigeria. Int. J. Gen. Med. 6 375-381 (2013).

182. Ike, S. O. Echocardiographic analysis of valvular heart diseases over one decade in Nigeria. Trans. R. Soc. Trop. Med. Hyg. 102, 1214-1218 (2008).

183. Ogbera, A. O., Adeleye, O., Solagberu, B. $\&$ Azenabor, A. Screening for peripheral neuropathy and peripheral arterial disease in persons with diabetes mellitus in a Nigerian University Teaching Hospital. mellitus in a Nigerian University
BMC Res. Notes 8, 533 (2015)

184. Oyelade, B. O., OlaOlorun, A. D., Odeigah, L. O., Amole, I. O. \& Adediran, O. S. The prevalence of peripheral arterial disease in diabetic subjects in south-west Nigeria. Afr. J. Prim. Health Care Fam. Med. 4, 354 (2012).

185. Dieynabou Sow, A., Toure, K., Basse, A. M. $\Sigma$ Ndiaye, M. M. Prognosis of spontaneous hemorrhagic stroke in people under 55 in Senegal, a developing country in Africa: a series of 53 cases. Med. Sante Trop. 26, 170-174 (2016).
186. Danesi, M. A., Okubadejo, N. U., Ojini, F. I. \& Ojo, O. O. Incidence and 30-day case fatality rate of first-ever stroke in urban Nigeria: the prospective community based Epidemiology of Stroke in Lagos (EPISIL) phase II results. J. Neurol. Sci. 331, 43-47 (2013).

187. Cossi, M. J. et al. Stroke: prevalence and disability in Cotonou, Benin. Cerebrovasc. Dis. 33, 166-172 (2012).

188. Onwuchekwa, A. C., Tobin-West, C. \& Babatunde, S Prevalence and risk factors for stroke in an adult population in a rural community in the Niger Delta, south-south Nigeria. J. Stroke Cerebrovasc. Dis. 23 , 505-510 (2014).

189. Danesi, M., Okubadejo, N. \& Ojini, F. Prevalence of stroke in an urban, mixed-income community in Lagos, Nigeria. Neuroepidemiology 28, 216-223 (2007)

190. Agyemang, C. et al. Stroke in Ashanti region of Ghana Ghana Med. J. 46, 12-17 (2012)

191. Chelo, D. et al. Cardiac anomalies in a group of HIV-infected children in a pediatric hospital: an echocardiographic study in Yaounde, Cameroon. Cardiovasc. Diagn. Ther. 5, 444-453 (2015).

192. Tantchou Tchoumi, J. C. et al. Occurrence and pattern of congenital heart diseases in a rural area of subSaharan Africa. Cardiovasc. J. Afr. 22, 63-66 (2011).

193. Tantchou Tchoumi, J. C. et al. Pattern and clinical aspects of congenital heart diseases and their management in Cameroon. Bull. Soc. Pathol. Exot. 104, 25-28 (2011).

194. Nkoke, C et al. Echocardiographic pattern of rheumatic valvular disease in a contemporary sub-Saharan African pediatric population: an audit of a major cardiac ultrasound unit in Yaounde, Cameroon. BMC Pediatr. 16, 43 (2016)

195. Tantchou Tchoumi, J. C. \& Butera, G. Rheumatic valvulopathies occurrence, pattern and follow-up in rural area: the experience of the Shisong Hospital, Cameroon. Bull. Soc. Pathol. Exot. 102, 155-158 (2009).

196. Jingi, A. M. et al. The spectrum of cardiac disease in the West Region of Cameroon: a hospital-based cross-sectional study. Int. Arch. Med. 6, 44 (2013).

197. Ntep-Gweth, M. et al. Atrial fibrillation in Africa: clinical characteristics, prognosis, and adherence to guidelines in Cameroon. Europace 12, 482-487 (2010).

198. Dzekem, B. S. et al. Pulmonary hypertension in a Rural Area: prevalence, correlates and clinical features from the Shisong Cardiac Centre, Cameroon. Cardiovasc. J. Afr. 26, 14-15 (2015)

199. Menanga, A. P. et al. Patterns of cardiovascular disease in a group of HIV-infected adults in Yaounde, Cameroon. Cardiovasc. Diagn. Ther. 5, 420-427 (2015).

200. Lekoubou, A., Nkoke, C., Dzudie, A. \& Kengne, A. P. Stroke admission and case-fatality in an urban medical unit in sub-Saharan Africa: a fourteen year trend study from 1999 to 2012. J. Neurol. Sci. 350, 24-32 (2015)

201. Guerchet, M. et al. Epidemiology of peripheral artery disease in elder general population of two cities of Central Africa: Bangui and Brazzaville. Eur. J. Vasc. Endovasc. Surg. 44, 164-169 (2012).

202. Desormais, I. et al. Prevalence of peripheral artery disease in the elderly population in urban and rura areas of Central Africa: the EPIDEMCA study. Eur. J. Prev. Cardiol. 22, 1462-1472 (2015).

203. Sliwa, K., Acquah, L., Gersh, B. J. \& Mocumbi, A. O. Impact of socioeconomic status, ethnicity, and urbanization on risk factor profiles of cardiovascular disease in Africa. Circulation 133, 1199-1208 (2016).

204. Steyn, K et al. Risk factors associated with myocardia infarction in Africa: the INTERHEART Africa study. Circulation 112, 3554-3561 (2005)

205. Sliwa, K. et al. Readmission and death after an acute heart failure event: predictors and outcomes in subSaharan Africa: results from the THESUS-HF registry. Eur. Heart J. 34, 3151-3159 (2013).

206. Damasceno, A. et al. The causes, treatment, and outcome of acute heart failure in 1006 Africans from 9 countries. Arch. Intern. Med. 172, 1386-1394 (2012)

207. World Health Organisation. Chronic disease and health promotion: the STEPS instrument and support materials. WHO http://www.who.int/chp/steps/ instrument/en/ (2016).

208. Watkins, D. et al. Seven key actions to eradicate rheumatic heart disease in Africa: the Addis Ababa communique. Cardiovasc. J. Afr. 27, 184-187 (2016).

209. Mayosi, B. et al. The Drakensberg declaration on the control of rheumatic fever and rheumatic heart disease in Africa. S. Afr. Med. J. 96, 246 (2006).

210. Barth, D. D. et al. Rationale and design of the African group A streptococcal infection registry: the AFROStrep study. BMJ Open 6, e010248 (2016).
211. Mayosi, B. M. et al. Prednisolone and Mycobacterium indicus pranii in tuberculous pericarditis. N. Engl. J. Med. 371, 1121-1130 (2014)

212. Sliwa, K. et al. Bi treatment with hydralazine/nitrates versus placebo in Africans admitted with acute HEart Failure (BA-HEF). Eur. J. Heart Fail. 18, 1248-1258 (2016)

213. Etches, V., Frank, J., Di Ruggiero, E. \& Manuel, D. Measuring population health: a review of indicators. Annu. Rev. Public Health 27, 29-55 (2006).

214. United Nations Environment Programme. Africa environment outlook 3: our environment, our health UNEP http://www.unep.org/pdf/aeo3.pdf (2013).

215. Transparancy International. Corruption Perceptions Index 2015. Transparency.org https:// www.transparency.org/cpi2015/ (2016).

216. The African Economic Outlook 2016. Sustainable cities and structural transformation. African Economic Outlook http://www.africaneconomicoutlook.org/en/theme/ sustainable-cities-and-structural-transformation (2016).

217. Bain, L. E. et al. Malnutrition in Sub-Saharan Africa: burden, causes and prospects. Pan Afr. Med. J. 15, 120 (2013).

218. Silva-Matos, C. \& Beran, D. Non-communicable diseases in Mozambique: risk factors, burden, response and outcomes to date. Global Health 8, 37 (2012).

219. Heaton, T. B., Crookston, B., Pierce, H. $\&$ Amoateng, A. Y. Social inequality and children's health in Africa: a cross sectional study. Int. J. Equity Health 15, 92 (2016).

220. Kingue, S. et al. The VALVAFRIC study: a registry of rheumatic heart disease in Western and Central Africa. Arch. Cardiovasc. Dis. 109, 321-329 (2016).

221. Kilewo, C. et al. Hypertension in pregnancy among HIV-infected women in sub-Saharan Africa: prevalence and infant outcomes. Afr. J. Reprod. Health 13, 25-36 (2009).

222. Ojji, D., Stewart, S., Ajayi, S., Manmak, M. \& Sliwa, K. A predominance of hypertensive heart failure in the Abuja Heart Study cohort of urban Nigerians: a prospective clinical registry of 1515 de novo cases. Eur. J. Heart Fail. 15, 835-842 (2013).

223. Gebreselassie, K. Z. \& Padyab, M. Epidemiology of hypertension stages in two countries in sub-Sahara Africa: factors associated with hypertension stages. Int. J. Hypertens. 2015, 959256 (2015)

224. Engel, M. E. et al. Prevalence of rheumatic heart disease in 4720 asymptomatic scholars from South Africa and Ethiopia. Heart 101, 1389-1394 (2015).

225. Dokainish, H. et al. Heart failure in Africa, Asia, the Middle East and South America: the INTER-CHF study. Int. J. Cardiol. 204, 133-141 (2016).

226. Oldgren, J. et al. Variations in cause and management of atrial fibrillation in a prospective registry of 15,400 emergency department patients in 46 countries: the RE-LY Atrial Fibrillation Registry. Circulation 129 1568-1576 (2014)

227. O'Donnell, M. J. et al. Global and regional effects of potentially modifiable risk factors associated with acute stroke in 32 countries (INTERSTROKE): a case-control study. Lancet 388, 761-775 (2016).

\section{Acknowledgements}

A.K.K. is supported by the National Health and Medical Research Council of Australia Centre of Research Excellence to Reduce Inequality in Heart Disease (1044897). S.S. is supported by a National Health and Medical Research Council of Australia Fellowship (1041796).

\section{Author contributions}

All the authors contributed to researching data, discussions of content, writing the article, and to reviewing and editing the manuscript before submission.

\section{Competing interests statement}

The authors declare no competing interests.

\section{Review criteria}

Published articles were identified through a literature search of relevant bibliographic databases (EMBASE, MEDLINE, and PubMed). Studies were included if they examined any cardiovascular disease (CVD) epidemiological outcome in an African country. Preferential reporting on specific findings was given to the largest, most robust, and contemporary epidemiological reports focusing on each CVD subtype on a regional basis. The quantity and quality of research reports described in this Review reflect the predominantly lowresource setting of Africa with minimal research infrastructure and funding. The majority of reports are based on convenience sampling via regional centres servicing the local population and are mostly retrospective in nature. 